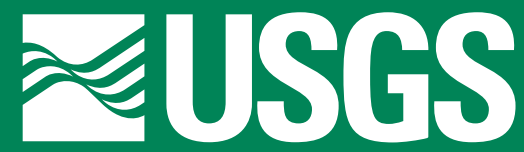

science for a changing world

\title{
Anchorage Urban Region Aeromagnetics (AURA) Project - Preliminary Geophysical Results
}

by R.W. Saltus ${ }^{1}$, P.J. Haeussler ${ }^{2}$, R.E. Bracken ${ }^{1}$, J.P. Doucette ${ }^{1}$, and R.C. Jachens ${ }^{3}$

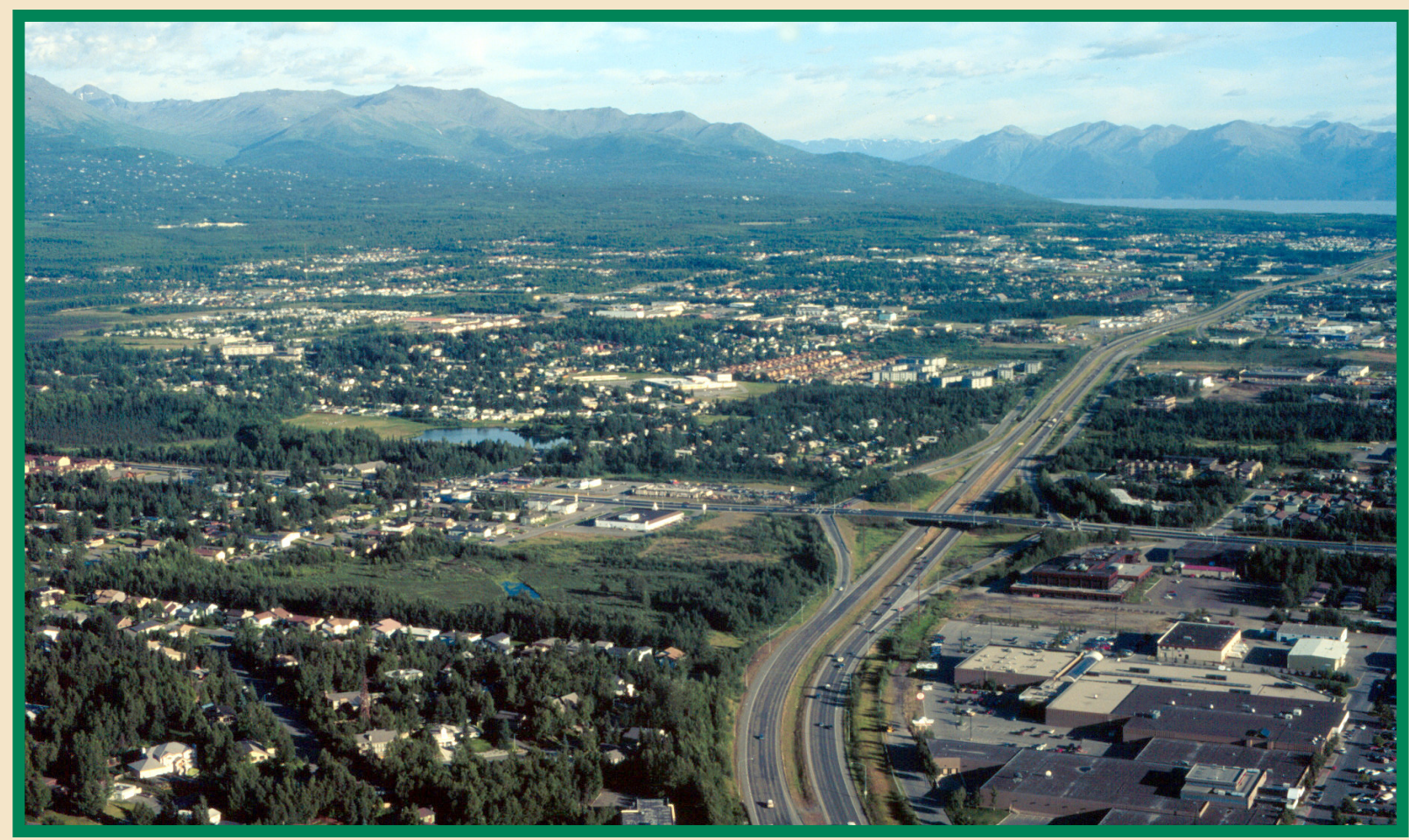

\section{Open-File Report 01-0085} 2001

This report is preliminary and has not been reviewed for conformity with U.S. Geological Survey editorial standards or with the North American Stratigraphic Code. Any use of trade, firm, or product names is for descriptive purposes only and does not imply endorsement by the U.S. Government.

\section{U.S. DEPARTMENT OF THE INTERIOR}

U.S. GEOLOGICAL SURVEY

${ }^{1}$ Denver, Colorado

${ }^{2}$ Anchorage, Alaska

${ }^{3}$ Menlo Park, California 


\section{Contents}

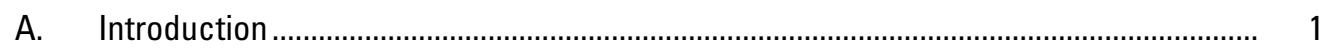

B. Description of the aeromagnetic data .................................................................... 1

C. Regional geophysical context and

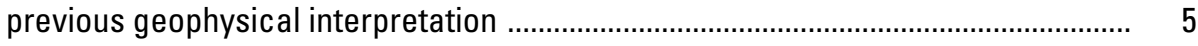

D. Depth to magnetic sources - matched filtering …………………………………...... 8

E. Linear feature analysis ....................................................................................... 14

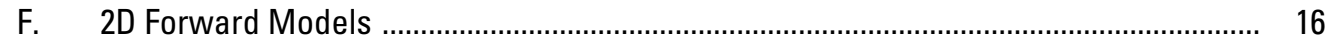

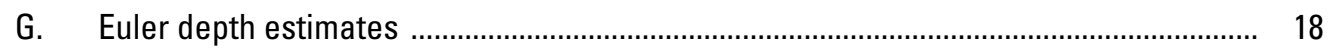

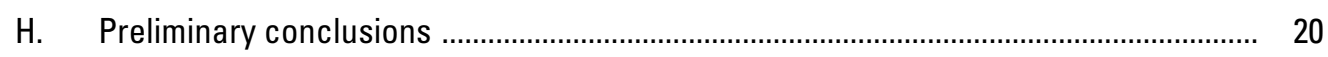

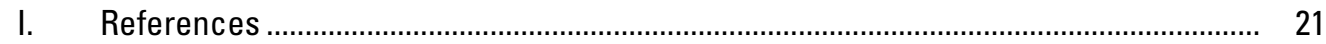

\section{Figures}

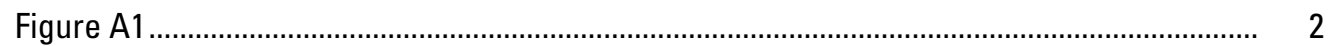

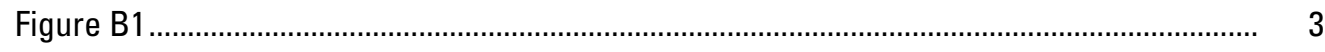

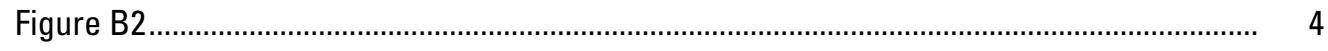

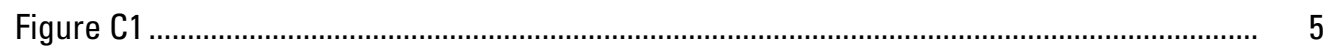

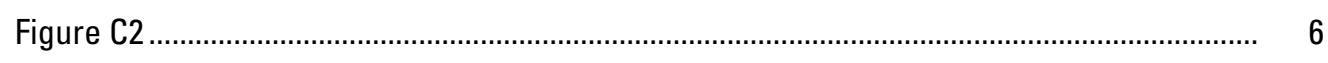

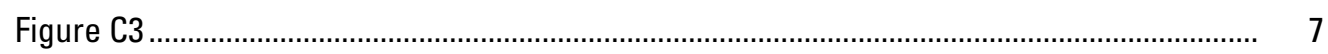

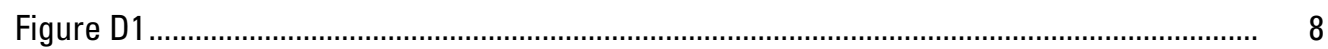

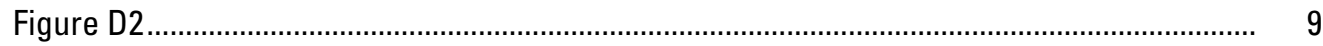

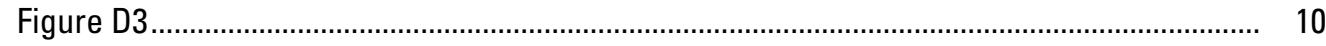

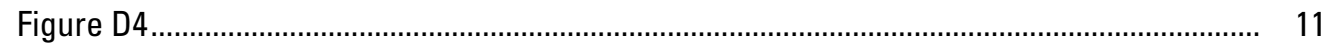

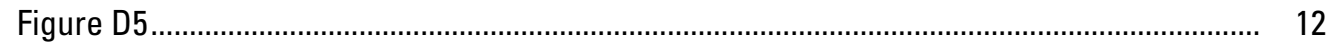

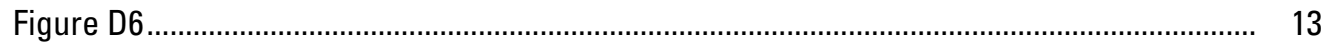

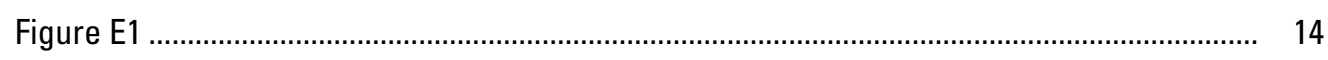

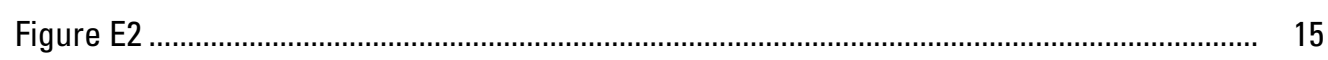

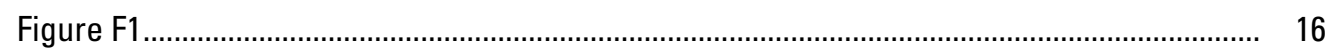

Figure F2

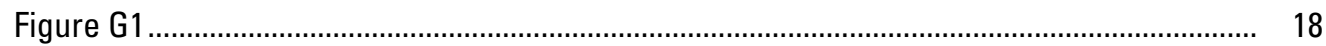

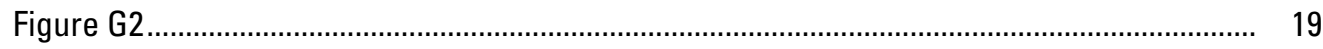

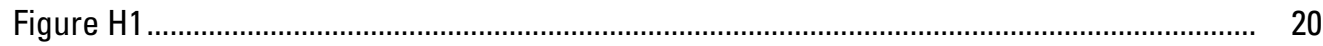

\section{Tables}

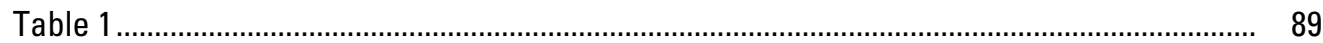




\title{
Anchorage Urban Region Aeromagnetics (AURA) Project - Preliminary Geophysical Results
}

\author{
by R.W. Saltus ${ }^{1}$, P.J. Haeussler ${ }^{2}$, R.E. Bracken ${ }^{1}$, J.P. Doucette ${ }^{1}$, and R.C. Jachens ${ }^{3}$
}

\section{A. Introduction}

The Anchorage urban region owes its spectacular waterfront setting and mountainous backdrop to dynamic tectonic processes that are continuing today. The upper Cook inlet contains over 5 $\mathrm{km}$ of sedimentary rocks deposited in a forearc setting. These sediments are now being folded and faulted by the same compressional forces that account for the dramatic topographic backdrop to the region. Better understanding of the three-dimensional structure of the upper Cook inlet sedimentary rock section promises to yield useful information relating to: (1) better assessment of earthquake (and possibly volcanic) hazards for the Anchorage urban area (including hazards threatening the oil and gas infrastructure in upper Cook Inlet), (2) effective planning of detailed geologic mapping in the region, and (3) improved models for occurrence of energy and mineral resources (including coal, oil and gas, placer gold, and industrial minerals).

Toward these goals, the U.S. Geological Survey (USGS) Anchorage Urban Region Aeromagnetic (AURA) project purchased about 15,000 line-miles of commercial aeromagnetic data spanning portions of the upper Cook inlet, Alaska (Figure A1). Images of these data paint a composite view of magnetic sources at several depth intervals that relate to geological and structural features in this region. Mathematical analysis of these data, constrained by additional gravity, seismic, and geologic information, yields maps and models of these features at a variety of depths. In this report we describe the basic features of the aeromagnetic dataset, give a regional and historical perspective on aeromagnetic feature interpretation for this area, and present preliminary interpretive results based on application of matched filtering, linear feature analysis, two-dimensional forward modeling, and Euler depth analysis to these data. For each interpretive method we give a brief introduction to the method, present the results of a preliminary application, and discuss its apparent utility to the general goals of the AURA project.

\section{B. Description of the aeromagnetic data}

The aeromagnetic survey was flown in September and October of 1993 and in September of 1994 by World Geoscience (World Geoscience was purchased by Fugro Airborne Surveys, Corp., in 2000). The survey lines were flown east-west with a spacing of $800 \mathrm{~m}$ (1/2 mile). Tie lines were flown northeastsouthwest with a spacing of about $3 \mathrm{~km}$. The nominal flight elevation was $150 \mathrm{~m}$ above ground. Measurements were made using a Split Beam Cesium Vapor magnetometer with a resolution of $0.001 \mathrm{nT}$ and a cycle rate of 0.1 second. This yields a sample interval of about 10 meters along each flight line. The survey was flown using fixed-wing aircraft (a Shrike Aerocommander was used in 1993 and a Piper Aerostar was used in 1994). Navigation was by GPS satellite positioning.

The measured data were corrected for diurnal variation, leveled using tie-line crossings, and then had the 1990 International Geomagnetic Reference Field (IGRF) removed by the contractor.

Our evaluation of the flight-line data obtained from the contractor indicated no systematic data quality problems. Several high-amplitude "bull's eyes" (circular or elliptical anomalies of less than 1 mile in diameter) are spatially correlated with oil and gas field production platforms and other large structures (e.g., Figure B1). Shaded relief display of the reduced and gridded (250 m interval) magnetic field data reveals some subtle features that require special attention. The most obvious example involves missing data on the eastern part of flight-line 30330 (about 35 miles south-southeast of Anchorage) which are manifested as slight breaks in cross-cutting trends in this region. In addition, a relatively pervasive, but subtle, crosshatch pattern appears over much of the data region (Figure B2). This appears as ripples in the magnetic profiles, which are shown in Figure B2. The amplitude of this pattern generally ranges from 2 to 15 $\mathrm{nT}$ - too large to be an artifact of the gridding process. Careful examination of these magnetic patterns and measured topographic clearance in the radar altimeter channel indicate these features are, at least in part, correlated with topography and probably result from magnetic effects of surficial material. These are short wavelength, low-amplitude features that do not appreciably affect the interpretation methods discussed below.

Based on careful examination of the data we feel that the data are best gridded at an interval of $2 / 5$ to $2 / 3$ of the flight-line spacing (grid intervals of about 300 to $500 \mathrm{~m}$ ) without inclusion of the tie-lines. This requirement arises because the original survey was flown with a flight height too low for the flight-line spacing (Reid, 1980). Said another way, additional detail is present in the flight-lines that cannot be effectively captured in gridding.

\footnotetext{
${ }^{1}$ Denver, Colorado

${ }^{2}$ Anchorage, Alaska

${ }^{3}$ Menlo Park, California
} 


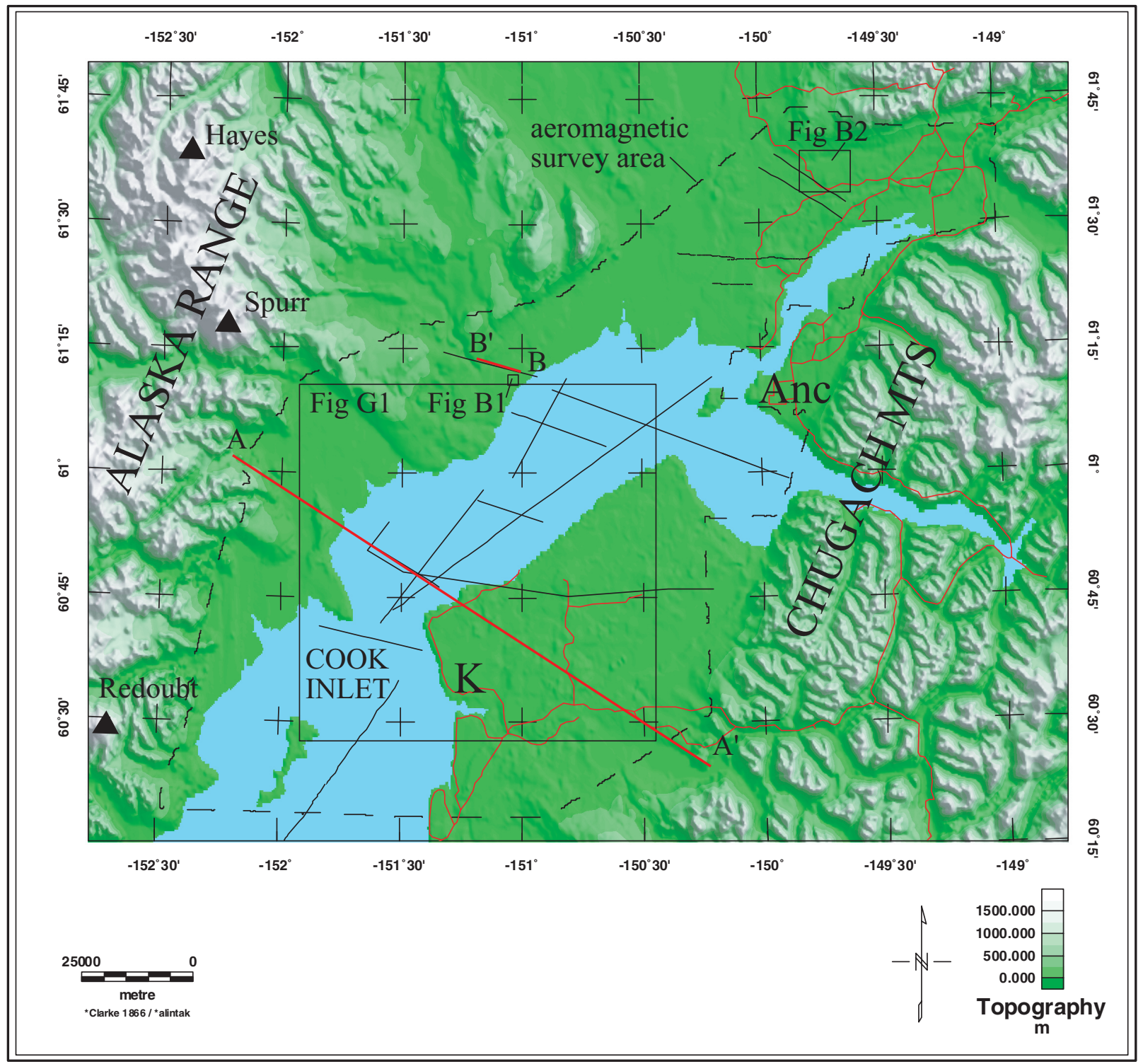

Figure A1. Index map of the upper Cook Inlet showing topography, geography, roads (red lines), seismic lines (black lines), 2D geophysical profiles (A-A' and $\left.B-B^{\prime}\right)$, outline of the aeromagnetic data discussed in this report, and locations of maps in figures B1, B2, and G1. Towns: $A$ = Anchorage, $P=$ Palmer, $W=$ Wasilla, $K=$ Kenai. Volcanos: Hayes, Spurr, Redoubt. 


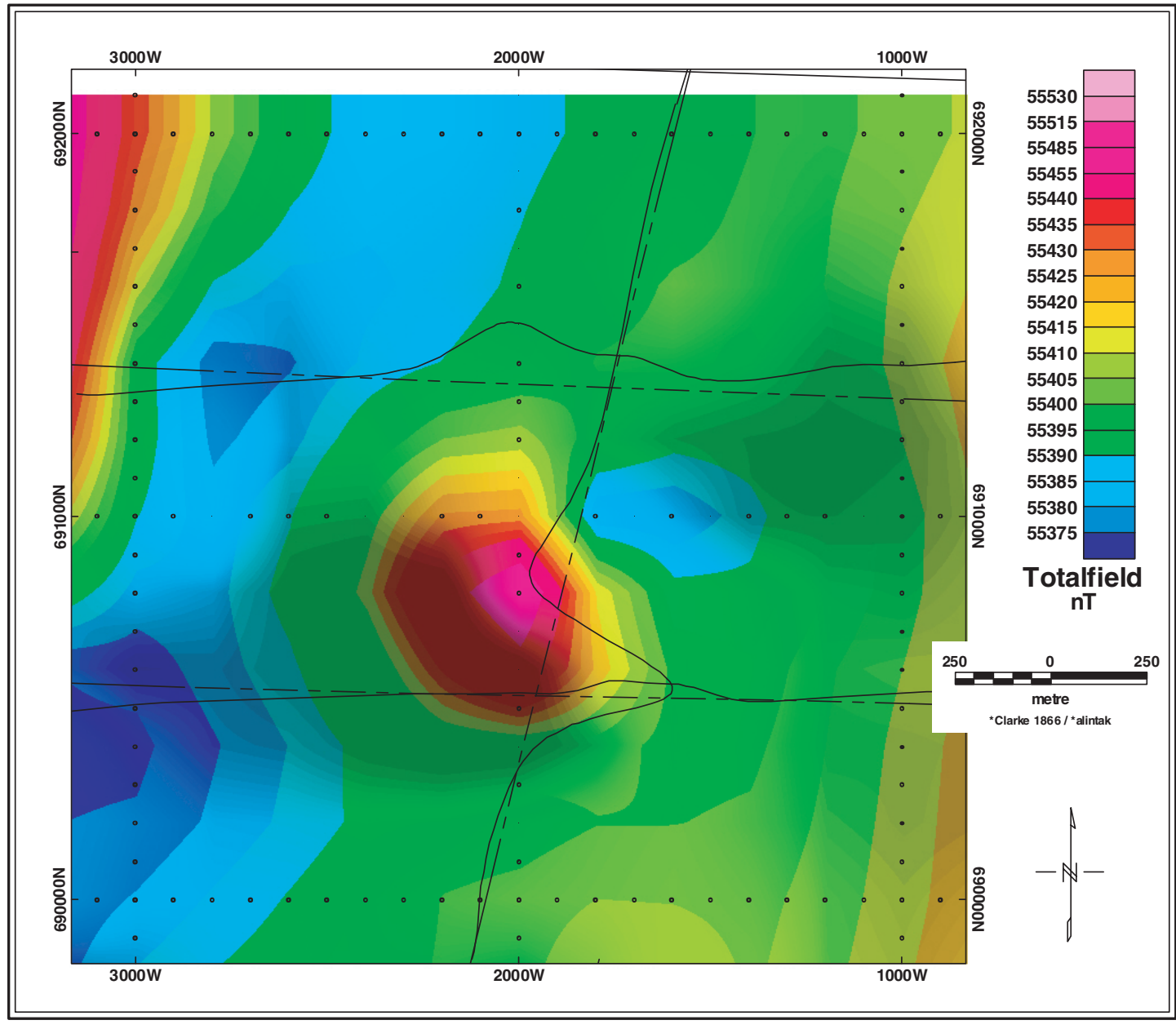

Figure B1. Illustration of magnetic anomaly at Beluga field assumed to be caused by a man-made structure. Dashed lines delimit 1-km grid squares. Dot-dashed lines show location of flightlines; solid-line curves are aeromagnetic profiles along the flightlines. The magnetic anomaly is about $100 \mathrm{nT}$ in amplitude and about $600 \mathrm{~m}$ from trough to trough. 


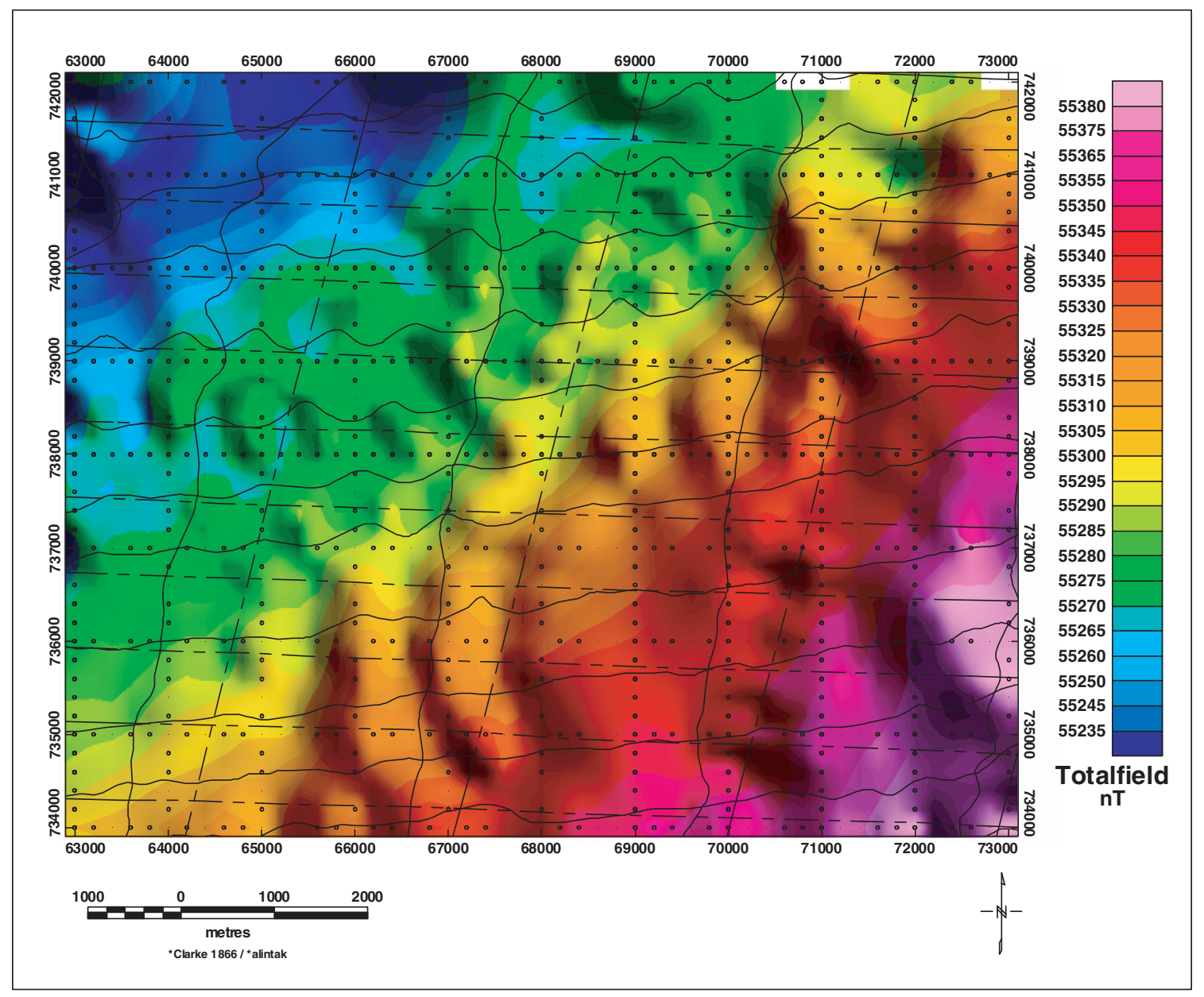

Figure B2. Illustration of crosshatched anomaly pattern related to magnetized topography. Dashed lines delimit 1-km grid squares. Dot-dashed lines show location of flightlines; solid curves are aeromagnetic profiles along the flightlines. Peak-to-trough amplitude of the short-wavelength anomalies range from 2 to $15 \mathrm{nT}$. The crosshatch pattern in the gridded data results because the flightlines are too widely spaced $(800 \mathrm{~m})$ relative to the height above the magnetic sources (here assumed to be nearly the flight height of $150 \mathrm{~m}$ ). 


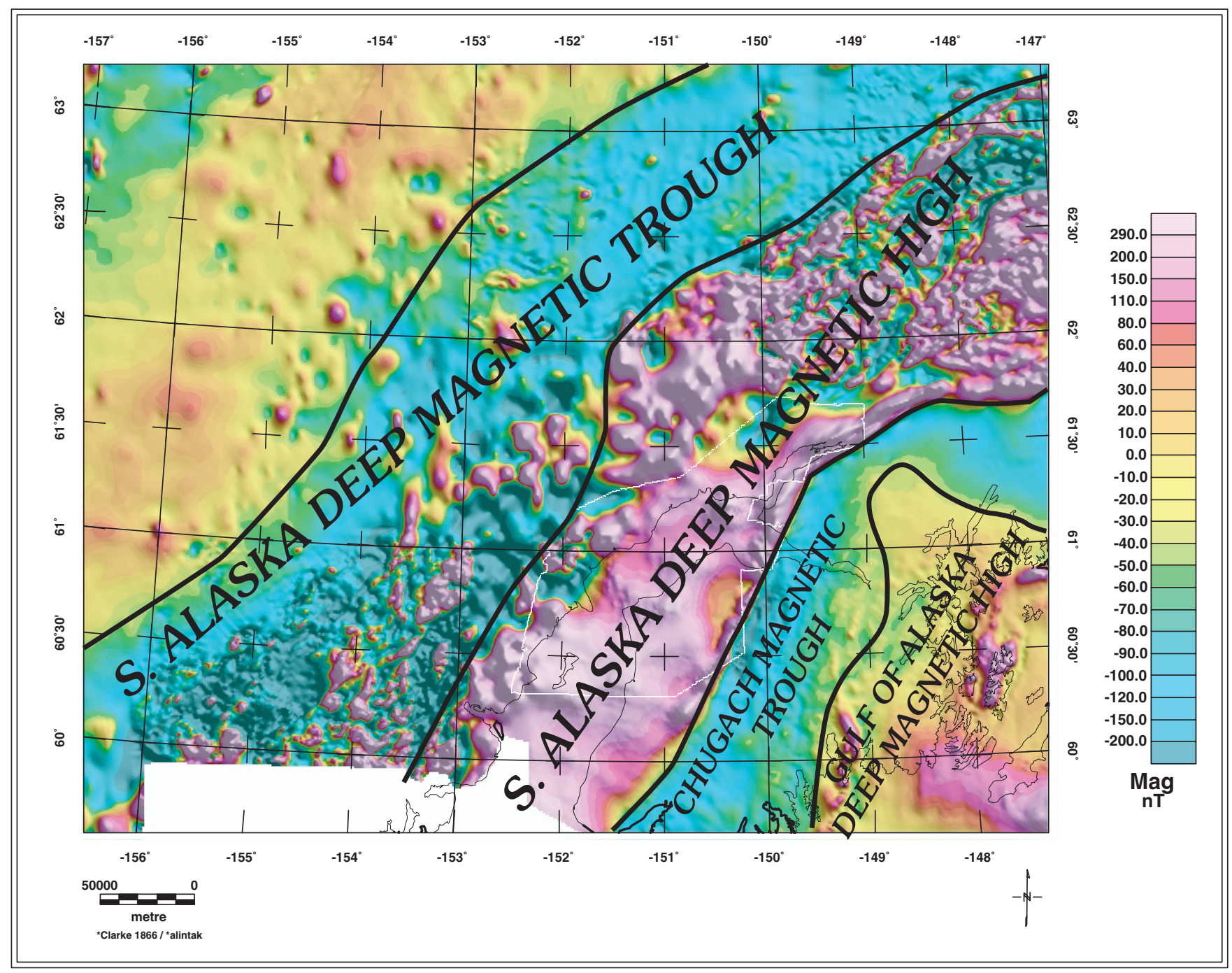

Figure C1. Magnetic map of surrounding region including long wavelengths in Anchorage region (subset from AKM grid of Saltus and others, 1999b). Regional magnetic zones are from Saltus and others (1999a) and were identified from 10-km upward continued data.

\section{Regional geophysical context and previous geophysical interpretation}

The aeromagnetic data discussed in this report fall within the broad, arcuate Southern Alaska Deep Magnetic High (Figure C1; Saltus and others, 1999a) - a zone of large-amplitude magnetic highs spatially associated with Jurassic and younger arc-related rocks and basement (parts of the Wrangellia composite terrane of Plafker and Berg, 1994). This highly magnetic zone can be modeled (Saltus and others, 1999b) as a crustal-scale block with a thickness of over $20 \mathrm{~km}$ and a bulk magnetic susceptibility of about $75 \times 10^{-3} \mathrm{SI}\left(6 \times 10^{-3} \mathrm{cgs}\right)$. This contrasts with modeled crustal bulk susceptibilities to the southeast of about $1 / 2$ this amount and to the northwest of about $1 / 10^{\text {th }}$ this amount. This high bulk susceptibility is argued to represent a mafic (oceanic affinity) bulk composition of this crustal block (Saltus and others, 1999a).

The northern part of the AURA study area (north of latitude $61^{\circ} \mathrm{N}$ ) falls in the interior Alaska region analyzed geophysically by Saltus and others (1997). Several "tectono-geophysical domains" were defined by examination of geophysical boundaries from regional gravity and magnetic data. The Southern Alaska Deep Magnetic High (Saltus and others, 1999a) can be subdivided here into the Wrangellia, Peninsular \#1, and Peninsular \#2 tectono-geophysical domains based on gravity and magnetic character (Saltus and others, 1997). Many of the features and boundaries of these domains were previously recognized and described by Griscom and Case (1983). The magnetically subdued region to the northwest of the Southern Alaska Deep Magnetic High is called the Southern Alaska Deep Magnetic Trough (Saltus and others, 1999a) and was identified as the Kahiltna tectono-geophysical domains by Saltus and others (1997). To the southeast lies the Chugach magnetic trough (Saltus and others, 1999a), also identified as the Chugach tectonogeophysical domain (Saltus and others, 1997).

Sparse isostatic residual gravity data for the Cook Inlet basin show a pronounced gravity low centered on the basin (Figure C2). A significant part of this low is probably caused by the accumulation of low-density sedimentary rocks in the basin, 


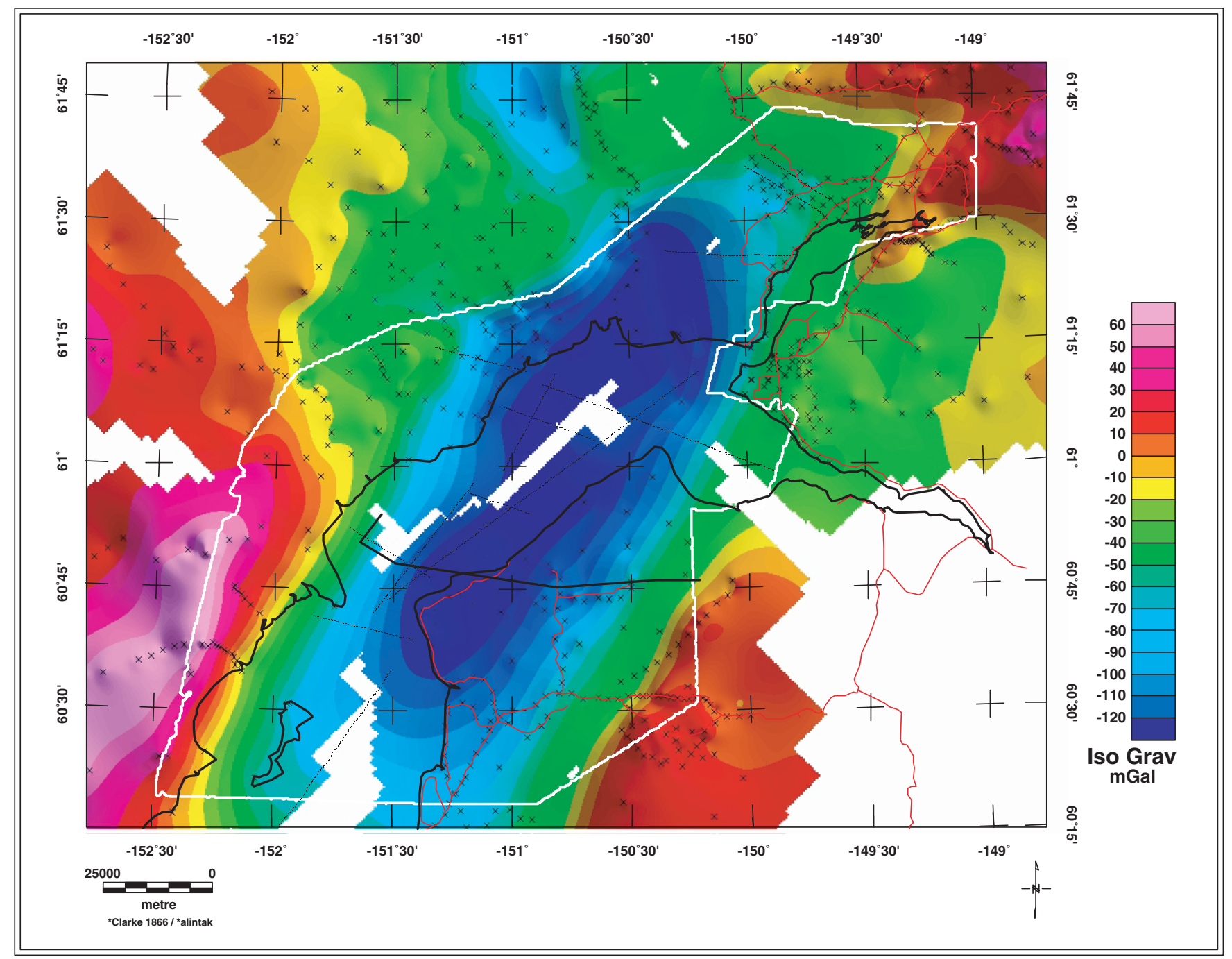

Figure C2. Isostatic residual gravity map based on gravity data from Robert Morin, USGS (written communication, 1999). The isostatic model parameters are: $25 \mathrm{~km}$ crustal thickness at sea level, $2.67 \mathrm{~g} / \mathrm{cm} 3$ topographic load density, and $0.4 \mathrm{~g} / \mathrm{cm} 3$ density contrast at the gravity Moho. Isostatic residual gravity values range from about +50 to $-150 \mathrm{mGal}$ with the lowest values coincident with the deepest parts of the basin. Red lines are roads; black lines are seismic lines; black outline shows the extent of the aeromagnetic data. $A=A n c h o r a g e$

but some portion of the low may also be caused by isostatic imbalance resulting from the dynamics of subducting the rigid Pacific plate beneath this region or by low-density sources within the basement.

A reconnaissance set of 42 east-west aeromagnetic profiles were flown over the upper Cook Inlet in 1954 and 1958 at an altitude of 2,500 ft (about $800 \mathrm{~m}$ ). The line spacing varied from 2 miles to 16 miles ( 3 to $25 \mathrm{~km}$ ) - too wide to permit detailed contouring of the data. In an interpretive report, Grantz and others (1963) name and discuss the following major regional magnetic features (which are labeled on a regional view of the modern data, Figure C3) as identified on the widely spaced profiles. (1) The high-amplitude, shallow source, magnetic anomalies to the northwest of the upper Cook inlet are called the "Mount Susitna anomaly group" and attributed to volcanic rocks and plutons of the Talkeetna mountains. (2) The boundary that marks the transition of these shallow-source anomalies to the broad basement anomalies beneath the Cook Inlet basin is called the "Moquawkie magnetic contact". (3) Southeast of this line they note the magnetic profiles are "smooth but broadly arched", and this arch (part of their "Cook Inlet magnetic anomaly") is inferred to represent "the presence at great depth of an elongate mass of magnetic and presumably igneous rock". (4) The high-amplitude, narrow anomaly that parallels the Border Ranges fault is termed the "Knik Arm anomaly". They attribute it to a narrow belt of plutons that "crop out in the axial part of the Seldovia geanticline".

Grantz and others (1963) compare the Cook Inlet magnetic anomaly with the magnetic anomaly observed over the Great Valley of central California and speculate that the origin of these anomalies may be similar. This is an interesting observation and merits some discussion here. It is now known that both the Cook Inlet and the Great Valley formed as forearc basins. In the preplate tectonic context of the time, Grantz and others (1963) interpreted the deep magnetic sources for both the Cook Inlet and Great Valley to represent "structurally competent rocks which, in late Mesozoic time, exerted a stabilizing influence on the crust beneath the Matanuska geosyncline and Great Valley". They characterized these broad, deep magnetic sources as indicative of the basement beneath geosynclinal troughs that were "tectonically only moderately unstable". 


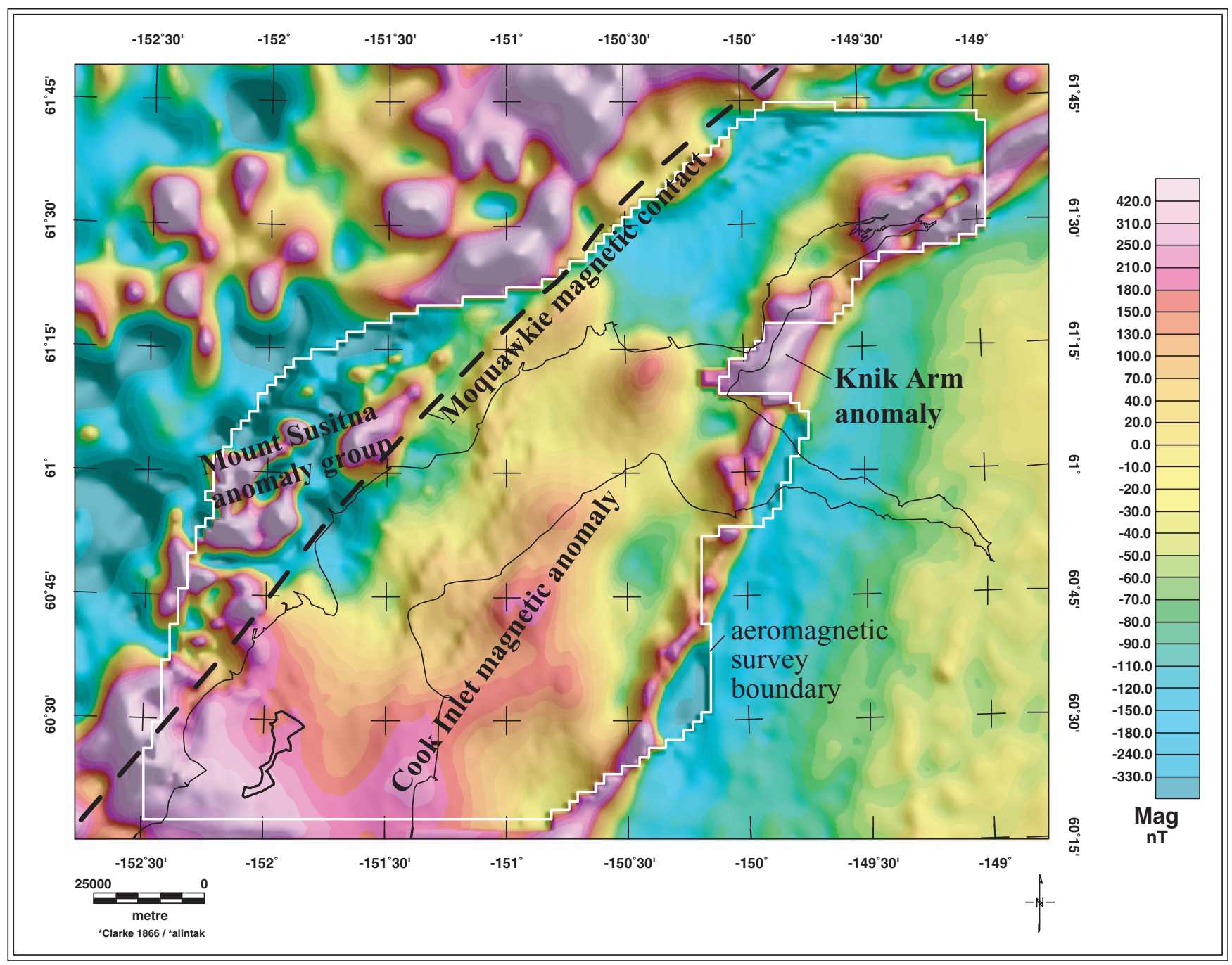

Figure C3. Long-wavelength magnetic features in the region surrounding the upper Cook Inlet. Anomaly names are from Grantz and others (1963). Dashed line marks the Moquawkie magnetic contact of Grantz and others (1963). White outline marks boundary of the aeromagnetic data analyzed in this report.

The Great Valley aeromagnetic anomaly was carefully analyzed by Cady (1975) who inferred that it arose from a "tectonically emplaced fragment of oceanic crust". In Cady's model this ophiolite sequence was detached from an eastward-dipping subduction zone as subduction stepped westward in Late Jurassic time. However, more recent analysis that incorporates seismic interpretation and the thickness of geophysically inferred bodies (Coleman, 1996; Coleman, in press) suggests that the deepseated magnetic material is more likely to be caused by in-place magmatic underplating related to Middle to Late Jurassic extension on the western edge of the incipient Sierran arc. By analogy, we could postulate that the deep-seated magnetic sources for the Upper Cook Inlet magnetic anomaly may be underplated mafic rocks related to forearc extension. This model predicts a positive gravity effect from the underplated mafic rocks, at odds with the large gravity low present over the Cook inlet.

A possible modification to this interpretation (Roy Hyndman, personal communication) is that the highly magnetic basement body is a zone of serpentinization resulting from de-watered fluids off the down-going slab. This model predicts a gravity low from the serpentinized rocks. This model is tested below in the section on two-dimensional modeling.

The "Knik arm anomaly" of Grantz and others (1963) is a part of a discontinuous magnetic anomaly that can be traced for more than $1000 \mathrm{~km}$ along the Border Ranges fault (Burns, 1982; Griscom and Case, 1983; Case and others, 1985). This anomaly has been analyzed in some detail along strike in the Valdez quadrangle some $150 \mathrm{~km}$ to the east of the AURA study area (Burns, 1982; Case and others, 1985). Burns (1982) correlated the anomaly with a mapped gabbroic body and modeled it as steeply dipping to the south and moderately dipping to the north with about $6 \mathrm{~km}$ total depth and magnetic susceptibilities ranging from about $50 \times 10^{-3}$ to over $100 \times 10^{-3}$ SI. Case and others (1985) attribute the anomaly to rocks of the Tazlina mafic-ultramafic plutonic belt that appears to be caught up in the suture between the Peninsular terrane to the north and the Chugach terrane to the south. Within the Anchorage quadrangle, Jurassic diorites and tonalites correlate with portions of this anomaly trend. 


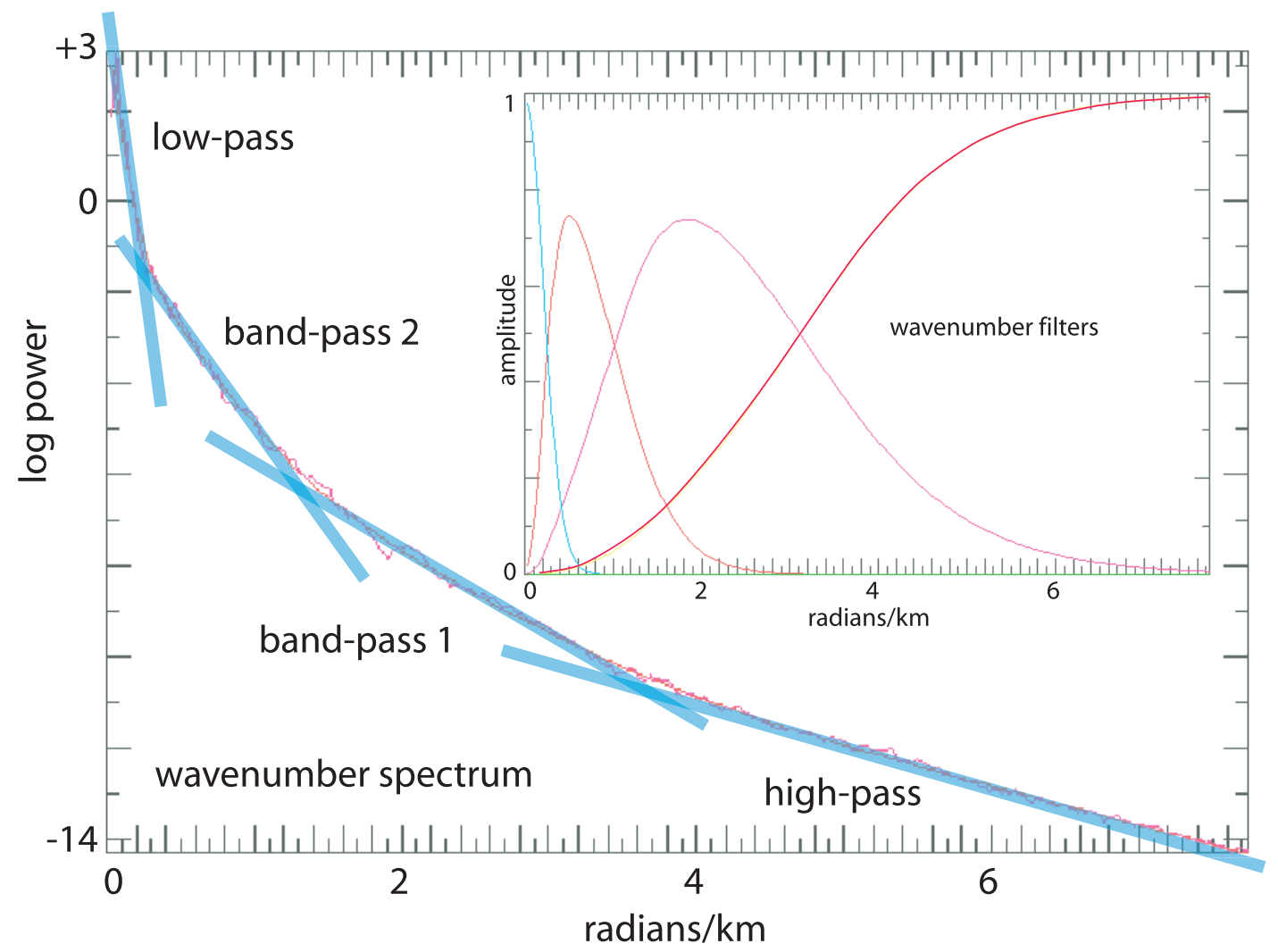

Figure D1. Radially averaged power spectra and matched filters. The highest power is present in the lowest wavelengths (left side). The highest wavelength features (which include noise) have the lowest power. The blue line segments show the four linear segments picked by hand to start the iterative process of defining a set of matched filters (Syberg, 1972; Phillips, 1997). The four resulting lowpass, bandpass, and highpass filters are depicted in the inset graph.

\section{Depth to magnetic sources - matched filtering}

In general, aeromagnetic features related to deeper magnetic sources will be broader (longer wavelength) than features related to shallower sources. By analysis of the frequency spectrum of magnetic field data it is possible to design band-pass filters to isolate the magnetic features arising from magnetic sources at different depths (providing the depths are sufficiently distinct). We use the matched filtering method (Syberg, 1972) as implemented by Phillips (Phillips, 1997) to separate the magnetic field of the upper Cook Inlet into four discrete wave-number divisions. Examination of the radially averaged power spectrum of the aeromagnetic data (Figs D1, D2) suggests that the curve can be approximated by at least four linear sections, representing the expression of magnetic sources at four different depth levels. By fitting the spectrum of the filters to this overall spectrum we can define a set of four "matched filters" (Fig D1) for subdividing the data. The specifications for these filters are given in Table D1.

The Phillips (1997) implementation of matched filtering is a multi-step method. First, the user hand-picks linear segments to approximate the power curve (Fig D1). Then, working from shortest to longest wavelengths, then the program iterates from those initial choices to produce the best match to the curve. We
Table D1 - Matched frequency specifications

\begin{tabular}{lrc}
\hline Name & Depth $\mathbf{( k m )}$ & Radians Type \\
\hline shallow (high pass) & 0.5 & 0.0073 dipole \\
band 2 (bandpass) & 1.6 & 0.2 dipole \\
band 1 (bandpass) & 4.4 & 3.3 dipole \\
deep (low pass) & 12.2 & 6.3 halfspace \\
\hline
\end{tabular}

were not able to produce a converging fit using fewer than four levels. Thus, our model seems to be the minimum number of dipole layers over a halfspace basement that will fit the data.

The longest wavelengths (band 1, representing a lowpass Fourier filter) probably represent variations in the magnetic properties (and to some extent the depth) of the crystalline basement rocks in this region. Mathematically this filter represents a magnetic half-space with its top at a depth of about $12 \mathrm{~km}$ (Table D1, Fig D3). The magnetic features in the basement probably reflect mafic intrusion resulting from forearc spreading (see section $\mathrm{C}$ above).

The next shortest wavelength band (band 2, Fig. D4) represents a layered source at a nominal depth of $4.4 \mathrm{~km}$. The patterns in this wavelength band might indicate fluctuations in intensity 


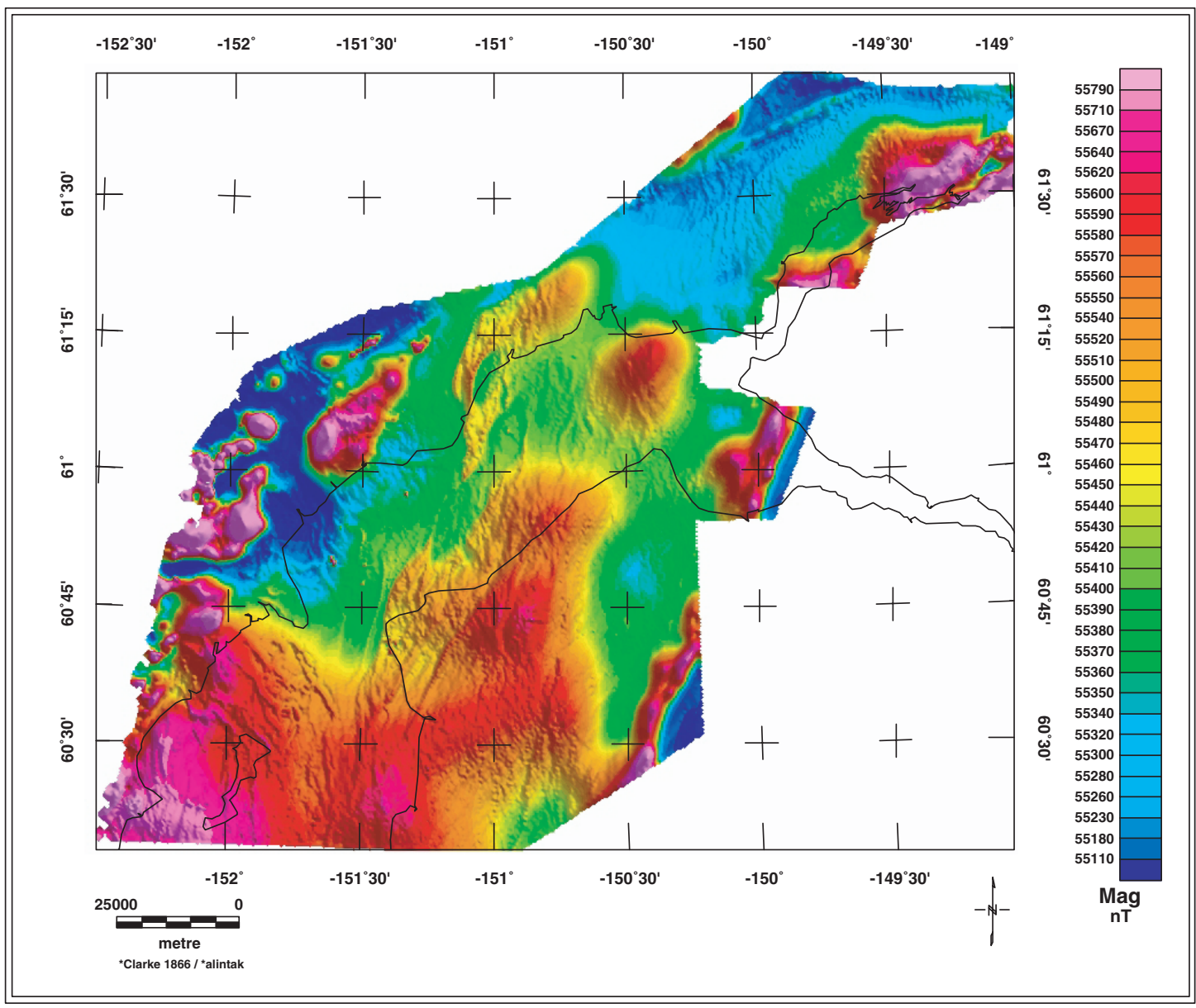

Figure D2. Total field aeromagnetic map. This map shows the measured magnetic field after removal of the very long wavelength International Geomagnetic Core Field (IGRF). The total field magnetic data contain a wide range of anomaly wavelengths reflecting sources at a variety of depths.

and/or depth of a magnetic layer within the mid-basin stratigraphy, or fluctuations of the base of a shallower magnetic layer.

Magnetic features in the next shortest band (band 3) represent sources at a nominal depth of $1.6 \mathrm{~km}$. The patterns in this wavelength window give rise to most of the linear features traced and mapped in the next section (Figure D5).

The shortest wavelength band (band 4, highpass filter) represents a combination of patterns in the shallowest magnetic sources as well as noise in the data arising from a variety of sources (some of which are described in section B above; Figure D6).

Matched filtering appears to be appropriate and effective on these data. There is a clear separation between the very shallow sources (bands 3 and 4 ) and the broad basement sources (band 1). The shallow source maps (Figs D5 and D6) appear to be directly applicable to estimation of lateral continuity of shallow structures. The intermediate sources (band 2) appear to be a combination of sources that in some cases appear to relate to the patterns of the shallow bands, in some cases to the deeper band, and, perhaps, also to intermediate sources between the two. One obvious problem with applying the matched filtering technique to the entire data set at once is that the thickness of the sedimentary section (and thus, the depth to the pre-Tertiary basement) varies throughout the survey area. We plan to experiment further by applying matched filtering to subsets of the entire dataset. Another approach to this problem would be through the use of wavelet filters instead of standard Fourier filters. Unfortunately wavelet tools are not as readily available or understood as standard Fourier filters. 


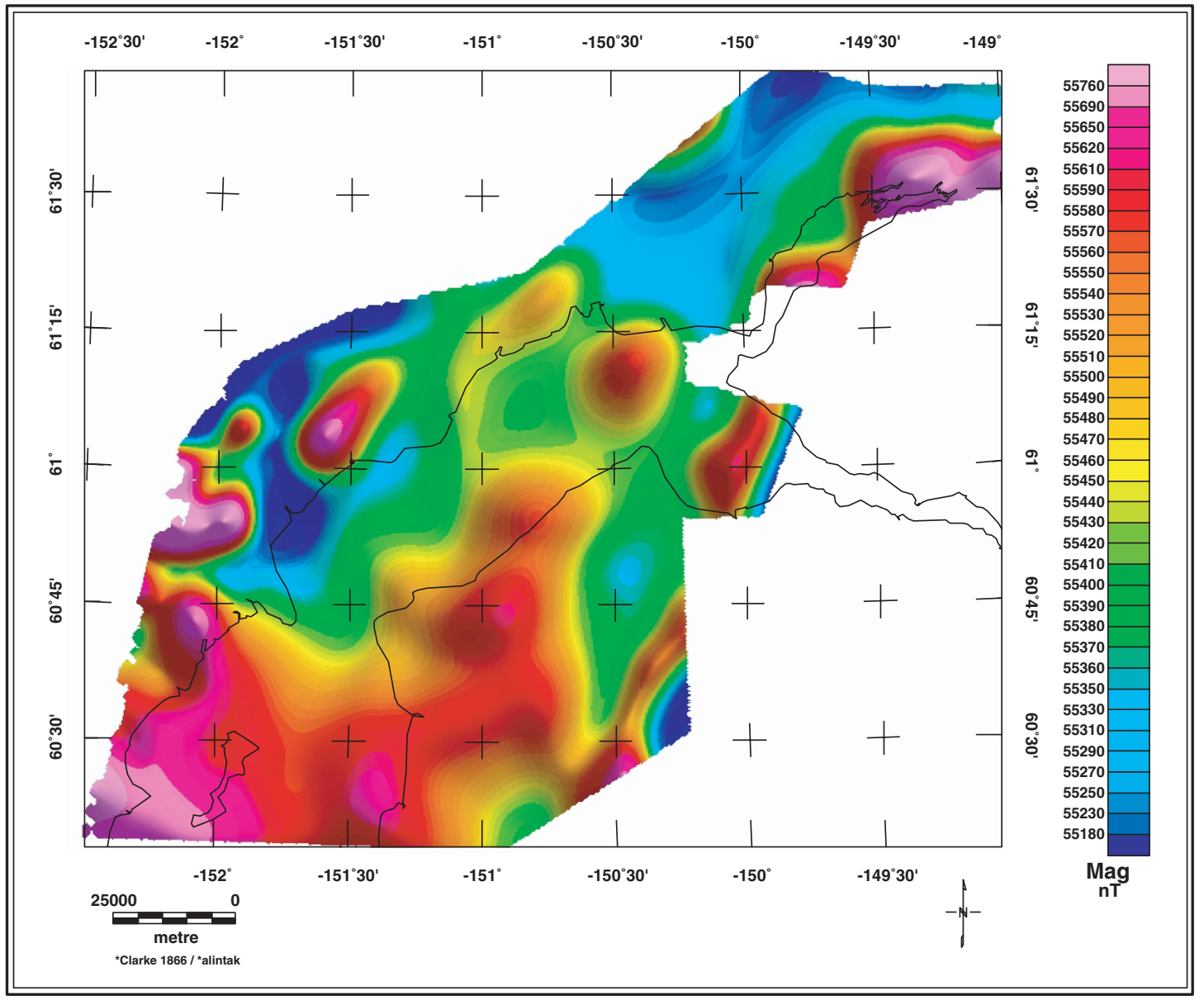

Figure D3. Basement (lowpass) magnetic features. This map shows magnetic features selected by the lowpass filter defined in Figure D1. These long-wavelength anomalies are primarily caused by deep sources. 


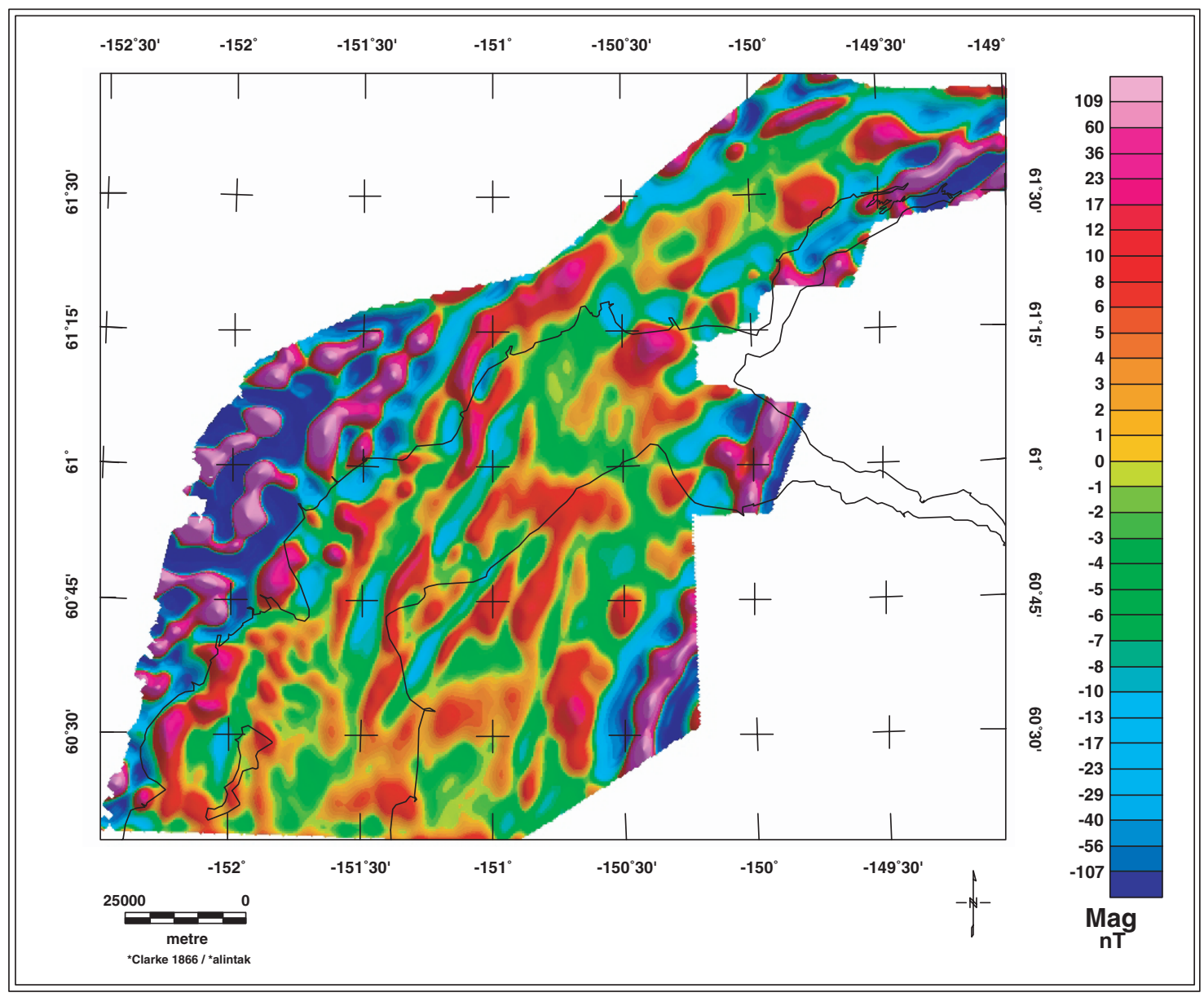

Figure D4. Moderate wavelength (bandpass) magnetic features. This map shows magnetic features selected by the bandpass 2 filter defined in Figure D1. These anomalies are caused by sources with intermediate depths. 


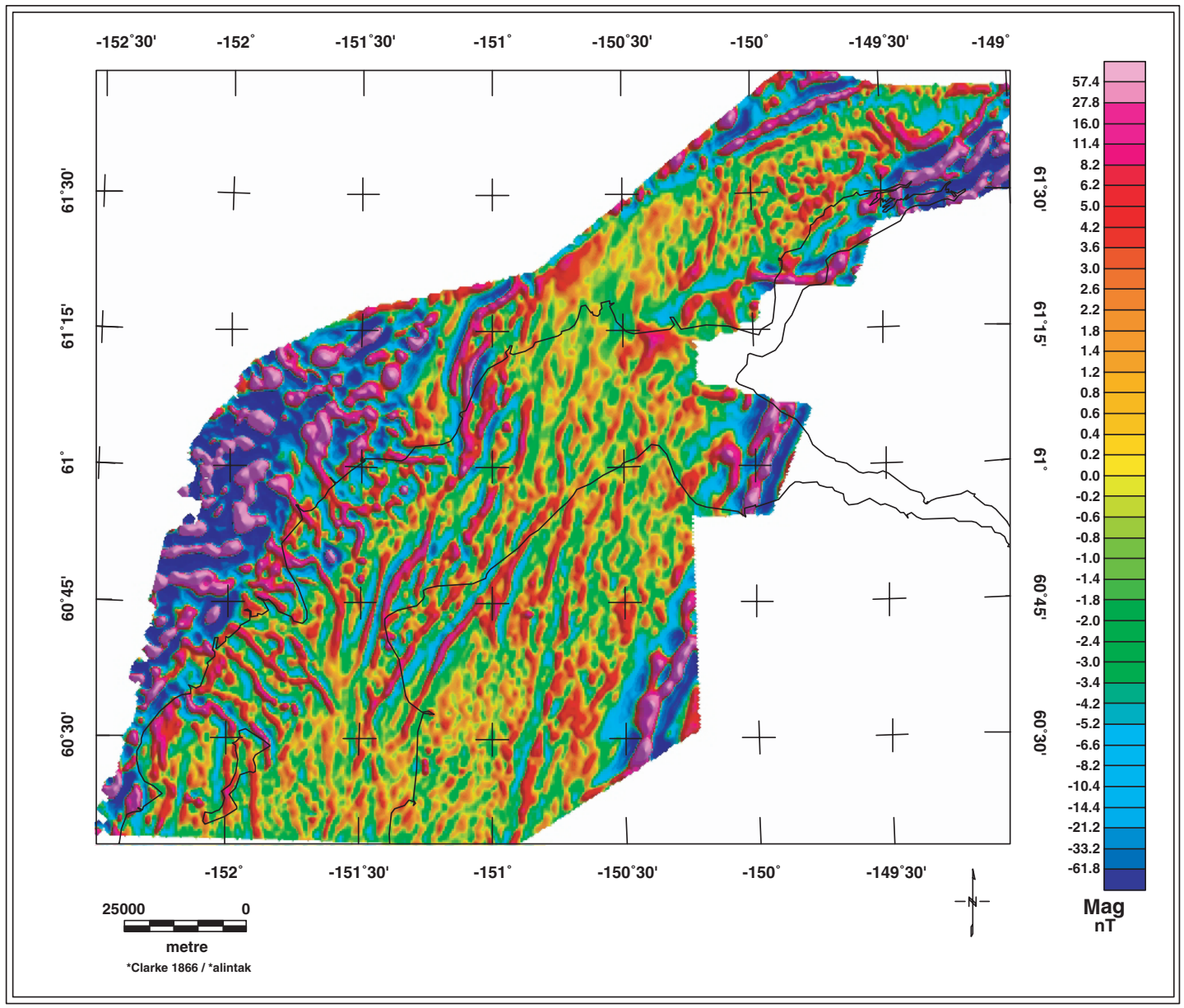

Figure D5. Short wavelength (shallow bandpass) magnetic features. This map shows magnetic features selected by the bandpass 1 filter defined in Figure D1. These anomalies are caused primarily by shallow sources. 


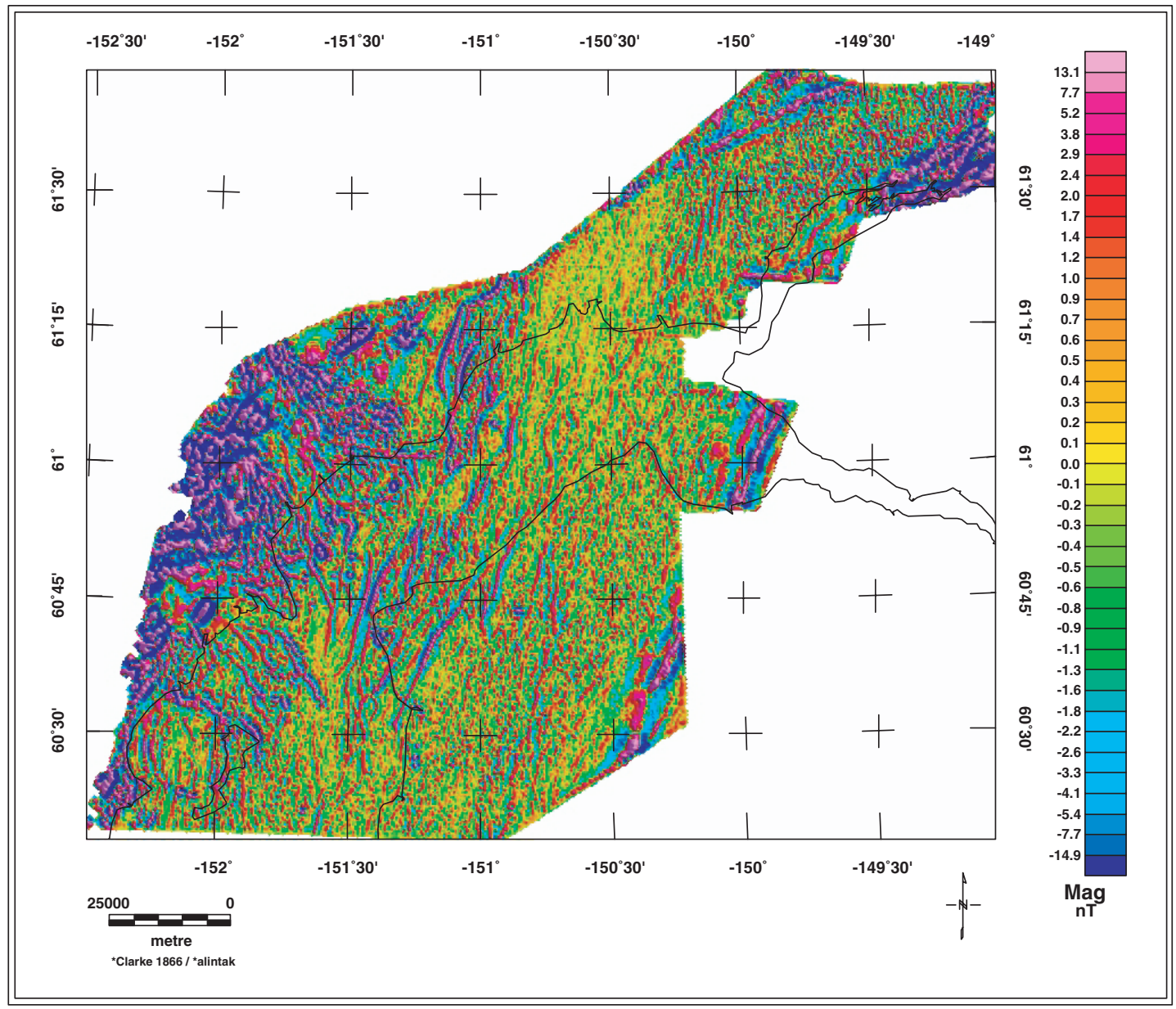

Figure D6. Shortest wavelengths (highpass) magnetic features. This map shows magnetic features selected by the highpass filter defined in Figure D1. These anomalies are caused by very shallow sources and by noise. 


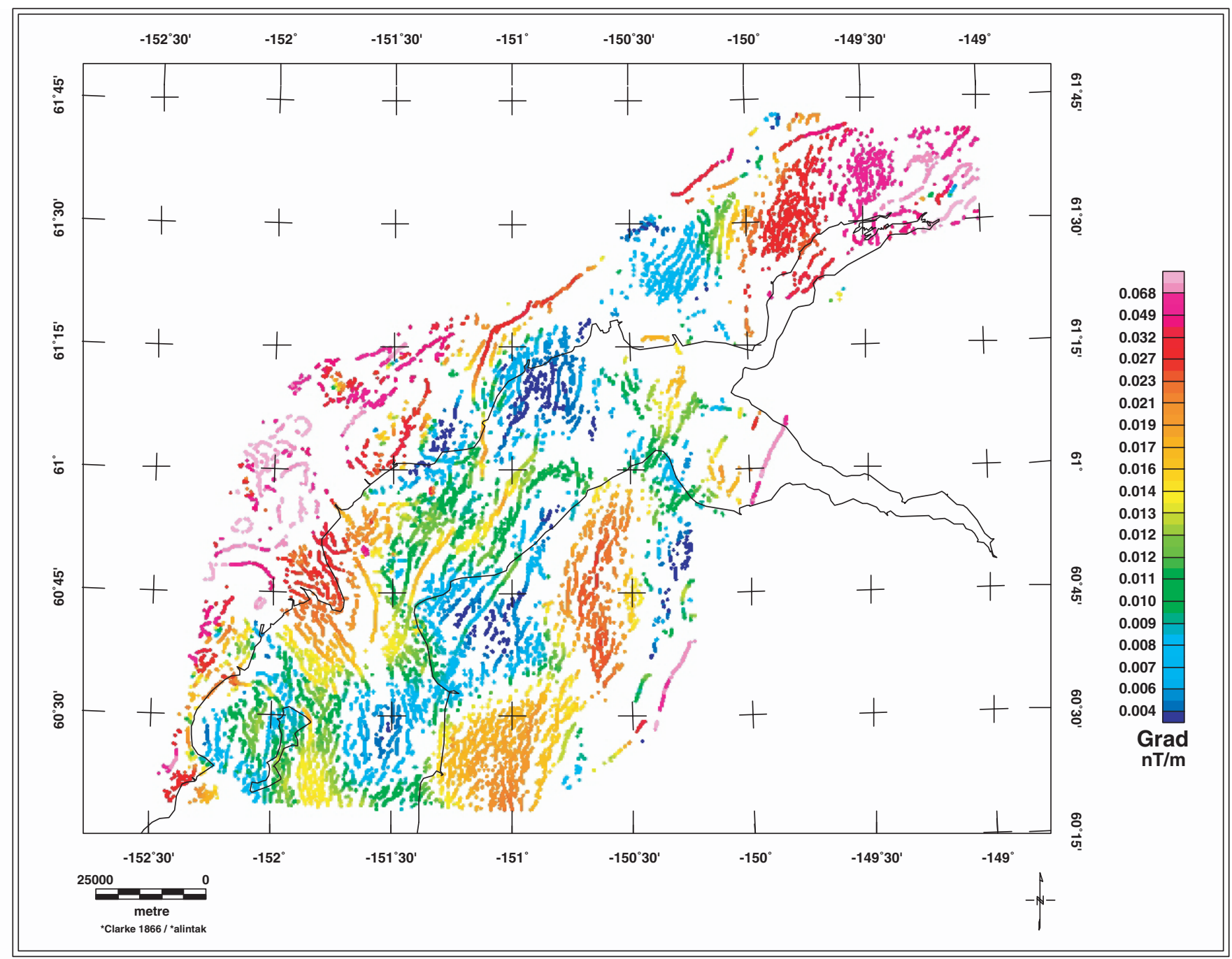

\section{E. Linear feature analysis}

We applied the three-step automatic method for identifying horizontal gradient maxima as location estimates of the edges of magnetic source bodies (Cordell and Grauch, 1985; Blakely and Simpson, 1986) in order to automatically locate potentially significant geological contacts. Following this method we first calculated the pseudogravity transform (Baranov, 1957) to convert the magnetic data to the equivalent gravity field that would be observed if density varied proportionally to magnetic susceptibility. This step simplifies the potential field response of basic source bodies to a single gradient rather than the multiple gradients that arise because of the dipolar nature of magnetic anomalies. We then calculated the magnitude of the horizontal gradient of this pseudogravity field. The final step involves identifying point locations of maxima in this field. The result is a set of "maxspots" that are discrete point estimates of the horizontal location of the edge of a magnetic source body (Figure E1, color-coded by gradient magnitude). These point estimates must be joined together to form lines that represent meaningful geologic boundaries. The conversion of discrete maxspots to linear features is typically done by hand and involves subjective interpretation.

Our hand picks of significant linear magnetic features are depicted as black lines in Fig E2. We have also experimented with an automatic procedure for converting maxspots into lines. The red lines on Figure E2 depict lines generated using the "gridline" function of Arc/Info (a proprietary GIS software package by ESRI). The automatic procedure removes much of the subjective interpretation involved in hand-digitizing linear features from the maxspots. In either case, these features undoubtedly arise from a variety of geometrical sources. Many of them probably indicate the flanks of folds and faults that affect the shallowest magnetic strata. If this interpretation is correct, these features are longer than previously mapped fold structures (Magoon and others, 1976; Haeussler and others, 2000).

Our experimentation with automatic line tracing from the calculated maxspots appears very promising. Figures E1 and E2 represent linear boundaries generated from the total field (i.e., unfiltered) magnetic anomalies. Thus the lines may trace boundaries arising from any depth. This method should be applied to the matched filter depth slices (i.e., figures D2-D5) to produce features that are more suited to specific interpretation. 


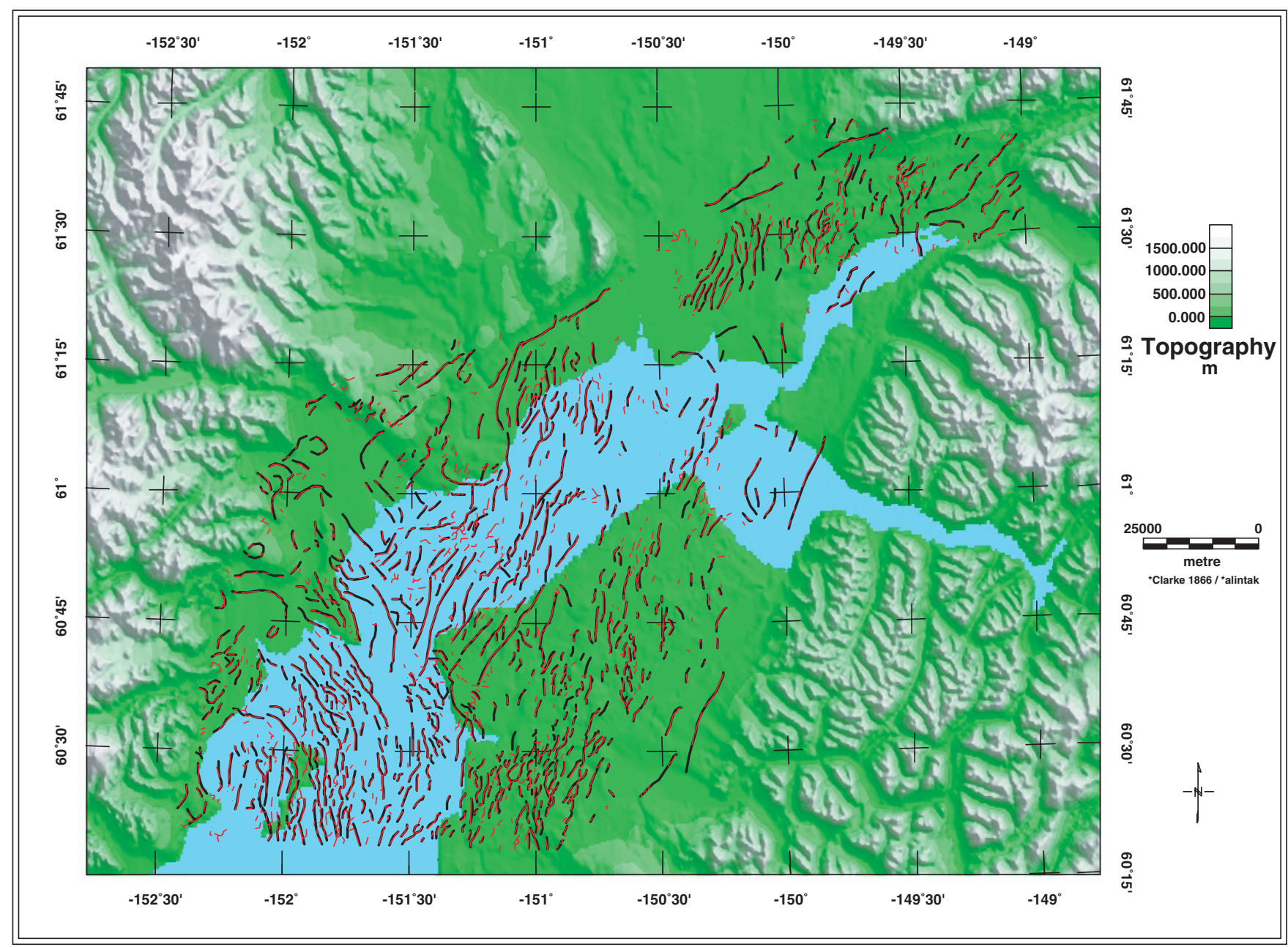

Figure E2. Hand-picked verses Automatic linear maximum gradient boundaries. Black lines are gradients traced by hand, red lines are traced automatically by computer. Horizontal gradient maxima indicate locations of boundaries between regions with contrasting magnetic properties. Here they likely arise from a variety of sources including truncation edges, folds, and faults that affect magnetic source beds. 

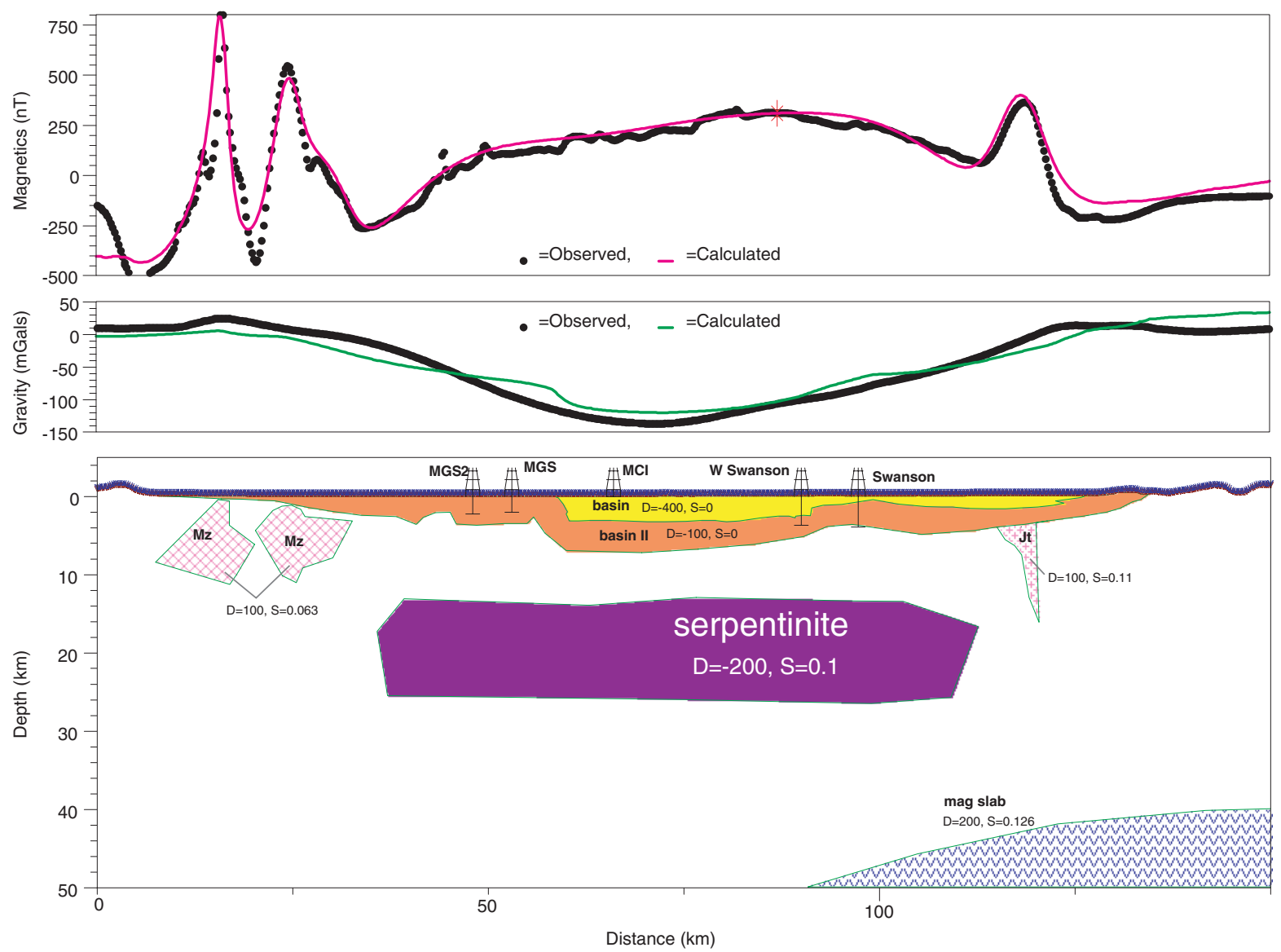

Figure F1. Regional two-dimensional northeast-southwest geophysical profile through the Middle Ground Shoal field and seismic line 210C,D. Geophysical body physical properties are density (D) in kg/m3 and susceptibility (S) in SI units.

\section{F. 2D Forward Models}

Forward modeling along two-dimensional profiles (Talwani and others, 1959; Blakely and Connard, 1989) is probably the most flexible tool for geologic interpretation of magnetic anomalies. Modern software allows for easy inclusion of model constraints from auxiliary datasets such as seismic images or well logs. Because of the uncertainties relating to trade-offs between magnetic layer thickness and susceptibility, incorporation of some kind of constraints (consciously or unconsciously) is essential to producing a defensible model. For all its flexibility, the profile forward modeling approach has several distinct drawbacks. First, it is a time-consuming exercise, ill-suited to automatic analysis. Second, it is often difficult to quantify the uncertainties in the models produced.

Images of industry seismic data, obtained and previously studied by Haeussler and others (2000), are used here as the basis for constructing 2D cross-sectional models of the magnetic and gravity data at two scales (locations on Figure A1). The regional model (Figure F1) incorporates constraints from seismic line 203-210C,D through the Middle Ground Shoal field (Haeussler and others, 2000). The detailed model (Figure F2) uses constraints from seismic line 285-1 through the Beluga field (Haeussler and others, 2000).
The northeast-southwest regional model (Figure F1) starts on the flanks of the Alaska Range and extends across a deep part of the Cook Inlet basin and across the Border Ranges fault into the Chugach Mountains (Figure A1). Isostatic residual gravity is about $150 \mathrm{mGal}$ lower in the middle of the basin than on the flanks. We have modeled the gravity variation as primarily caused by a two-tiered set of low-density sediments in the Cook Inlet basin, with the average total thickness of the sedimentary rocks controlled by seismic interpretation and well penetrations. We have chosen density contrasts of $-400 \mathrm{~kg} / \mathrm{m}^{3}$ and $-100 \mathrm{~kg} / \mathrm{m}^{3}$ for the shallower and deeper parts of the basin, respectively. The combined gravity effect from these two portions of the basin only accounts for about $1 / 2$ of the gravity low. If we assign a low density contrast of $-200 \mathrm{~kg} / \mathrm{m}^{3}$ to the deep, magnetic body (which would be reasonable if the deep geophysical body represents a serpentinized zone), then we can approximately match the overall gravity low. Realistic modeling of the gravity data requires incorporation of a deep low-density source.

The regional magnetic profile (Figure F1) consists of a broad, $>500 \mathrm{nT}$ swell with superimposed short-wavelength highs and lows of $\pm 40 \mathrm{nT}$ and less. The western flank of the profile has two short-wavelength highs $>500 \mathrm{nT}$. The eastern flank has an intermediate-wavelength high of $>200 \mathrm{nT}$. We model the central $>500 \mathrm{nT}$ swell with a voluminous body (labeled "serpentinite" in Figure F1) with a susceptibility of 


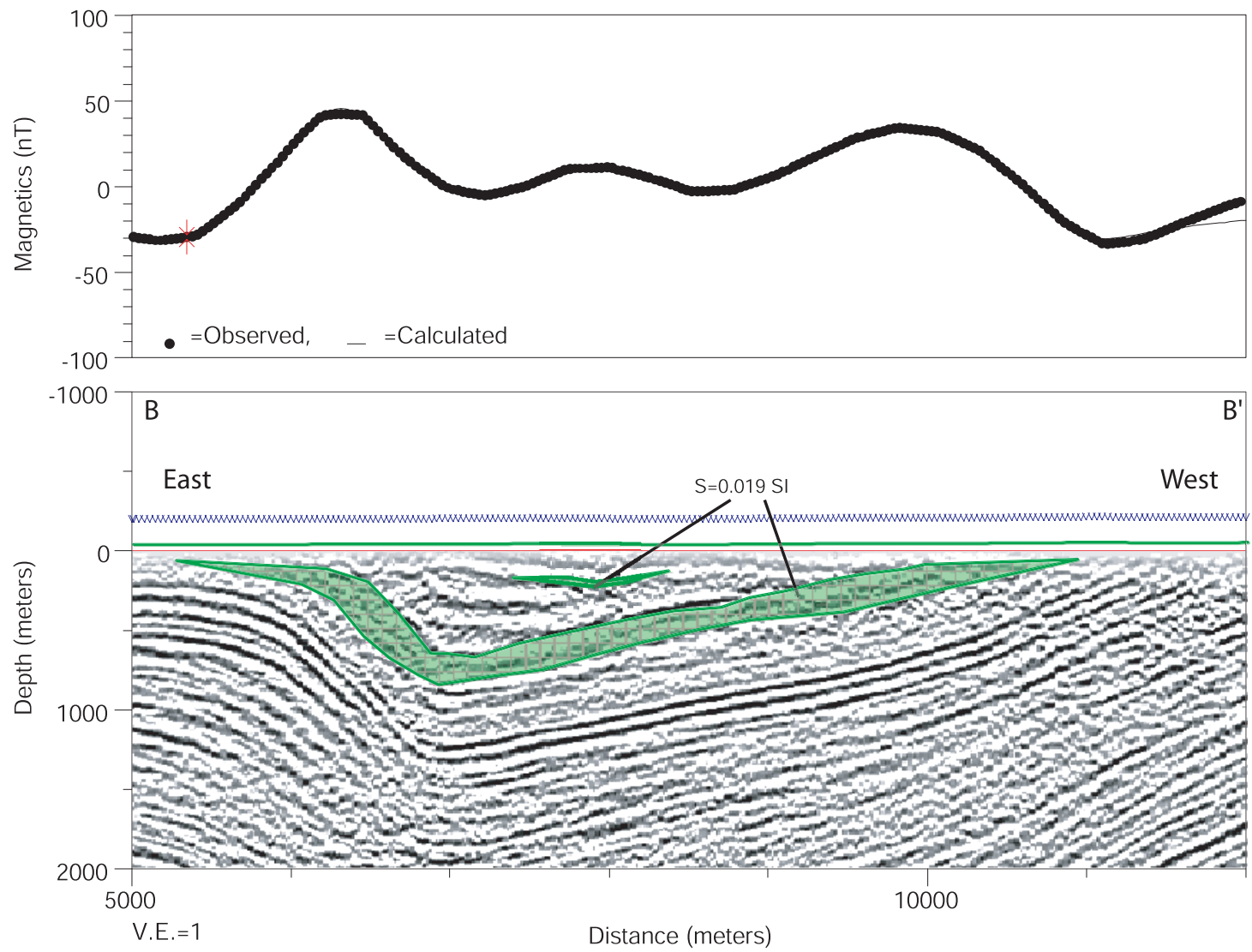

Figure F2. Detailed two-dimensional geophysical model along seismic line 285-1 near the Beluga field. The magnetic layers generally follow the seismic layering and have a susceptibility of $19 \times 10-3 \mathrm{SI}$.

$125 \times 10^{-3} \mathrm{SI}\left(10 \times 10^{-3} \mathrm{cgs}\right)$. If this body is inferred to be serpentinized mafic material, then we would expect this body to also be a negative gravity source and have modeled it as $-200 \mathrm{~kg} / \mathrm{m}^{3}$ relative to adjacent basement rocks. The short-wavelength, $>500$ $\mathrm{nT}$ magnetic highs on the western flank of the profile can be explained by Mesozoic intrusions with a modeled susceptibility of $60 \times 10^{-3} \mathrm{SI}\left(5 \times 10^{-3} \mathrm{cgs}\right)$. The intermediate-wavelength, $>200$ nT magnetic high on the eastern flank is modeled as caused by Jurassic tonalites (part of the Tazlina mafic-ultramafic complex) with a susceptibility of $110 \times 10^{-3} \mathrm{SI}\left(9 \times 10^{-3} \mathrm{cgs}\right)$. To fit the anomalies we also were required to include a gravity and magnetic source body at depth that corresponds to the down-going Pacific plate slab in this location.

To investigate the source geometry and magnetization implied by the short-wavelength $\pm 40 \mathrm{nT}$ and smaller anomalies, we model the filtered magnetic anomalies (from bands 3 plus 4 of the matched filtering discussed above) along a portion of seismic line 285-1 near the Beluga field (Figure A1, F2; Haeussler and others, 2000). This model shows that a layer (or layers) of magnetic rock several hundred meters thick with a bulk susceptibility of $19 \times 10^{-3} \mathrm{SI}\left(1.5 \times 10^{-3} \mathrm{cgs}\right)$ that follows the apparent seismic stratigraphy can produce the observed anomaly. These modeled magnetic layers (possibly caused by a relative abundance of igneous detritus in that zone) cause magnetic anomalies where they are truncated at shallow depths or are deformed structurally by folding and faulting.

Selective two-dimensional forward modeling is essential to demonstrating the viability of proposed interpretive models such as the proposed shallow magnetic interval(s) along seismic line 285-1 (Figure F2) and the total size of the proposed source for the basement magnetic high modeled along the Middle Ground Shoal regional profile (Figure F1). Some care is required in communicating the confidence and certainty associated with the models developed in this manner. 


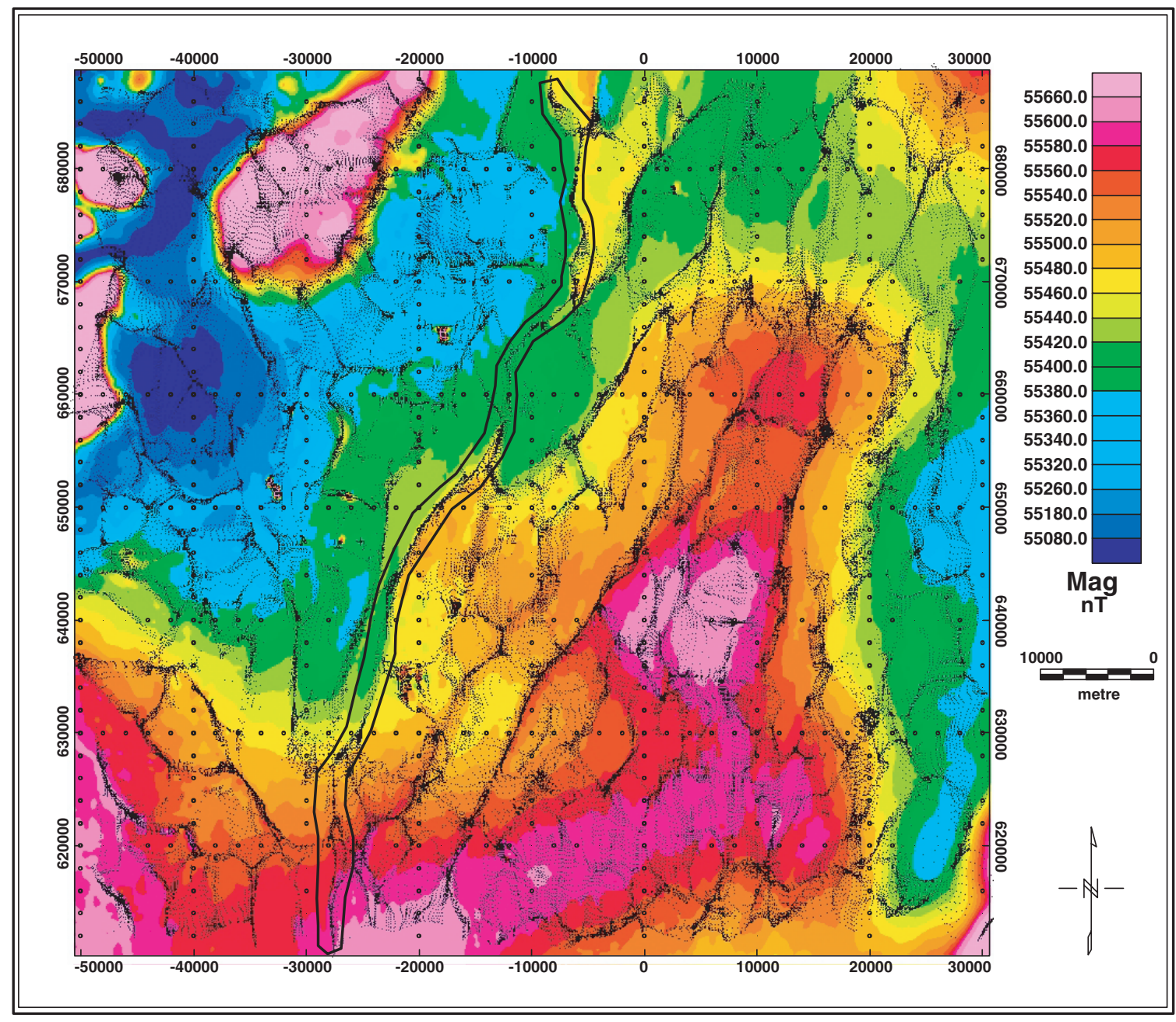

Figure G1. Map showing the aeromagnetic field of the sub-area used to evaluate the Euler 3D Deconvolution method. Black dots indicate the map locations of Euler solutions for an inversion with Structural Index $=0.5$, window size $=4,000$ $m$, maximum offset $=4,000 \mathrm{~m}$, maximum uncertainty in z-estimate $=30 \%$. Elongate NE-SW polygon surrounds the linear solution feature described in text and shown in figure G2.

\section{G. Euler depth estimates}

The "Euler method" is a nonlinear inverse method for estimating the depth and location of simple, idealized, potential field (gravity or magnetic) source bodies (e.g., Thompson, 1982; Blakely, 1995). The method has the advantage that it can be rapidly applied to magnetic data. Although we do not expect real world magnetic sources to be as idealized as the method assumes, in practice inferred sources tend to cluster around the edges of the presumed actual sources (Blakely, 1995).

The primary target of our analysis was the suite of shortwavelength, shallow-sourced anomalies (discussed above) that permeate the part of the aeromagnetic map over the thick sedimentary section beneath Cook Inlet (Figure D4). Our working hypothesis is that these anomalies are caused by magnetic sedimentary layers that are variously truncated at the sea floor, tightly folded, offset by faults, or otherwise disrupted as described in the previous section (e.g., Fig F2). Euler 3D deconvolution analysis (Reid and others, 1990) was applied to a subset of the upper Cook inlet detailed aeromagnetic data to define the 3-dimensional position of magnetic sources causing shallow, low-amplitude anomalies. We also tested methods for isolating the most reliable position estimates from the thousands of estimates that the method routinely produces. The Euler method evaluates the total magnetic-field anomaly (observed total magnetic field minus regional magnetic field) and its spatial derivatives by least squares inversion within a moving spatial window. Output consists of a set of points in three dimensions that represent estimates of the locations of magnetic sources that produce the measured anomalies.

We selected a roughly square sub area of the aeromagnetic map (approximately $80 \mathrm{~km}$ on a side, location on figure A1) on which to conduct the Euler deconvolution analysis (Figure G1). We performed the Euler deconvolution a number of times using different values for the structural index (SI, the parameter that characterizes the general geometry of the source by specifying the variation with distance or "fall-off rate" of the magnetic field it produces), the window size, and the maximum distance offset 


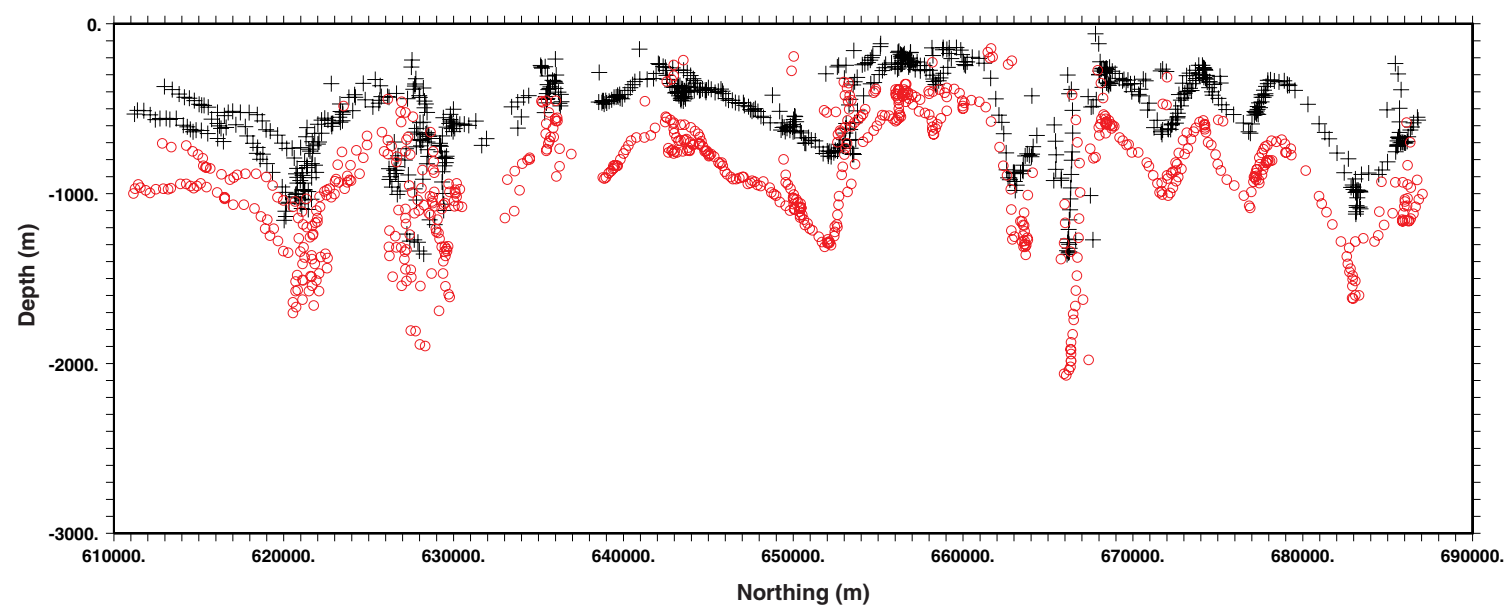

Figure G2. Plot of depth vs distance (NS) for Euler solutions associated with linear feature outlined on figure G1. Plus symbols represent solution for $\mathrm{SI}=0.5$ and circles represent solution for $\mathrm{SI}=1.0$.

from the center of the window. These tests were not exhaustive in exploring the full range of possible values, but do provide some insights into the effects of the parameters.

We first examined the effect of window size and the maximum distance offset from the center of the window. Solutions closer to the center of the window are expected, theoretically, to be more reliable than solutions significantly offset from the center. For window sizes of $2 \mathrm{~km}$ and $4 \mathrm{~km}$ and a maximum offset distance of $1 \mathrm{~km}$, the analysis yielded depths of $800 \mathrm{~m}$ or less, with no significant differences noted for the two different window sizes. For the same data set, increasing the maximum offset distance to $4 \mathrm{~km}$ resulted in maximum source depth estimates of nearly $4 \mathrm{~km}$.

Based on our interpretation that the sources of the short wavelength anomalies were disrupted sedimentary units, we expected the appropriate SI would be approximately 1.0. We tested SI values of 0.5, 0.75, 1.0, and 1.5. For SI values of 0.5, 0.75 , and 1.0, the Euler deconvolution yielded map distributions of estimated source locations that were quite similar (see Figure G1 for source locations for $\mathrm{SI}=0.5$ ), with the estimates typically defining individual linear patterns (Figure G1). These patterns were more diffuse and much less distinct for $\mathrm{SI}=1.5$.

When viewed in three dimensions, these individual linear patterns are actually steeply-dipping curtains of solutions extending from near the ground surface to a sharply defined cutoff at depth, a cutoff-depth that varies along strike. Typically, the smallest calculated uncertainties are associated with the deepest estimates. Figure G2 contains a cross section of source estimates for one of the linear features (traced on Fig. G1), showing only those estimates having locally the minimum uncertainty associated with depth. Figure G2 includes solutions both for SI $=0.5$ ('+' signs) and SI=1.0 (circles). Although solutions resulting from the two different values of the SI display a high degree of similarity in shape along strike, the depths are systematically different for the two solutions. The high degree of similarity between the two solutions suggests to us that the Euler deconvolution has defined a real feature in three dimensions, but deciding which solution is best is not obvious.

The limited tests of the Euler 3D deconvolution method reported above indicate to us that a large number of different solutions can be generated from the same potential field data set by varying the input parameters within reasonable limits. Deciding objectively which solution best represents the actual source distribution is extremely difficult. Searching for local (spatial) minima in the total suite of source location estimates is one approach to culling the total data set that seems to yield somewhat consistent results. For the present data set, the "tightness" of the map pattern of the location estimates for a given linear feature seems to be an effective indicator of the approximate SI, but probably only within a range of about 0.5 . Given the large number of possible solutions, perhaps the best way to use the Euler method with the present data set would be to generate some independent picks of magnetic source locations in 3 dimensions (from geology, well logs, seismic reflection profiles, direct forward modeling of select magnetic anomalies, etc.). These independent estimates could be compared with the various Euler solution sets to decide which set of parameters produces locations estimates that match the independent estimates, and then use this solution set to interpolate between known locations. 


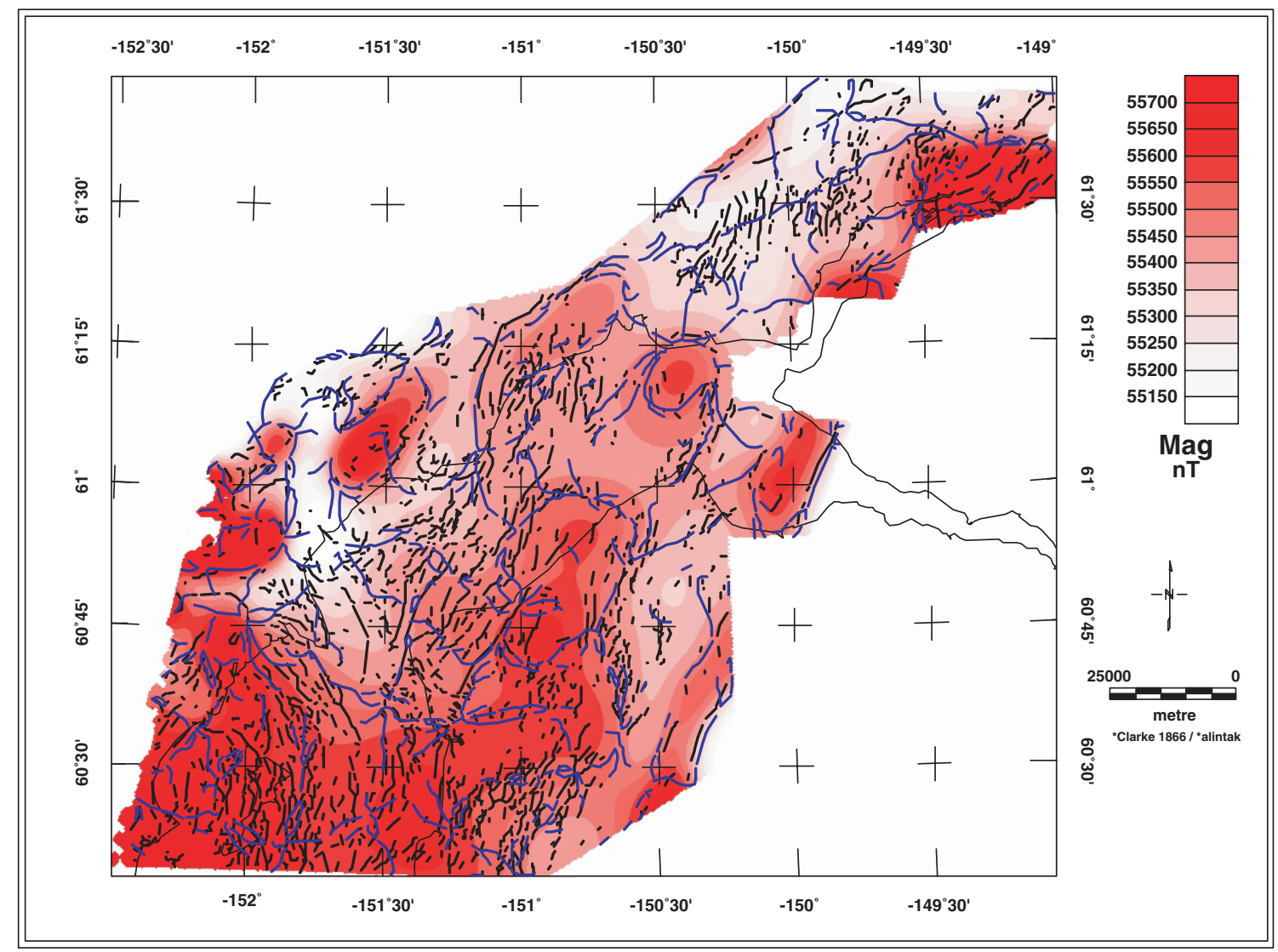

Figure H1. Preliminary geophysical interpretation map. Shades of gray are from the lowpass-filtered aeromagnetic data (Fig. D2). Blue lines delimit magnetic property boundaries based on pseudogravity gradients of the lowpass-filtered magnetics - these boundaries reflect sources in the pre-Tertiary basement. Red lines delimit boundaries based on analysis of pseudogravity gradients on the full magnetic dataset and primarily reflect shallow sources.

\section{H. Preliminary conclusions}

We have examined data quality issues, summarized the regional magnetic context, and investigated several interpretation strategies for the 800-m spacing aeromagnetic data spanning the upper Cook Inlet. This preliminary work will guide us in conducting more comprehensive interpretations of these data and adjoining data to the south, northwest, and over Anchorage itself. Our preliminary conclusions fall into two categories, (1) conclusions about the applicability and utility of the various interpretation methods in this region, and (2) geologic conclusions.

The aeromagnetic data, particularly over the deeper parts of the Cook Inlet basin, clearly contain anomalies related to sources from distinct depth levels. Wavelength filtering using the matched filtering technique appears very promising for isolating the signal from the shallow and deep sources. Two primary challenges present themselves here: (1) the frequency content of the basement geologic sources varies with depth to basement, so that filtering should really be applied within appropriate subsets of the entire dataset; (2) the matched filtering procedure involves subjective identification of linear trends in the overall power spectrum - this leads to a difficulty in quantifying uncertainties in the frequency separation. We intend to investigate appropriate subsetting of the data in on-going project work.
The scheme we have devised for repeatable, semi-automatic identification of linear source edges from the magnetic data appears very promising. The results will be most amenable to interpretation if the aeromagnetic data are first filtered into appropriate source depth levels.

Two-dimensional forward modeling, particularly when constrained by seismic and well log information, are critical to testing and demonstrating the viability of various geological interpretation hypotheses. This interpretation method is timeconsuming and requires numerous decisions and assumptions to be made by the interpreter. It can be quite difficult to quantify the uncertainties in the resulting models.

Euler depth estimation appears to be a very powerful tool for mapping magnetic sources in three dimensions, but appropriate filtering of the myriad solutions is time-consuming and subjective. It is important to use independent knowledge (or assumptions) about the magnetic sources to winnow a useful result from the solution cloud.

Anomaly patterns in the proprietary aeromagnetic data spanning upper Cook Inlet reflect geological structures on at least two and possibly three structural levels within the basin (summarized on Figure H1).

Long-wavelength anomalies reflect highly magnetic material within the pre-Tertiary basement such as voluminous, probably serpentinized, mafic intrusions. Gravity data appear more 
compatible with the serpentinized body model. Seismic tomography may have sufficient resolution to help choose between these models and the very different thermal histories that they imply.

The shortest wavelength anomalies appear to reflect stratigraphic terminations of magnetic layers against the surface as well as fold and fault structure and possibly lateral stratigraphic variation within parts of the Pliocene Sterling formation and (possibly) overlying Quaternary sediments. Linear features present in this part of the frequency spectrum may indicate a much longer northeast-southwest extent of some of the shallow (and young) fault-cored structures than previously recognized. Ground-based studies, including shallow seismic reflection and detailed geophysical profiling, where these anomalies may tie to surface outcrops (notably in the west side of the Kenai Peninsula) could help confirm this interpretation.

A third, intermediate, set of magnetic sources may also be visible in the magnetic data arising from depths on the order of $4 \mathrm{~km}$ within the central part of the basin. Alternatively, these intermediate wavelength features could reflect the bottom surface of the shallow magnetic marker layers. Further modeling will be necessary to determine whether this intermediate set of sources can be demonstrated to be distinct from the shallower and deeper sources.

\section{References}

Baranov, V., 1957, A new method for interpretation of aeromagnetic maps: Pseudo-gravimetric anomalies: Geophysics, v. 22, p. 359-383.

Blakely, R.J., 1995, Potential Theory in Gravity and Magnetic Applications: Cambridge University Press, 441 pp.

Blakely, R.J., and Simpson, R.W., 1986, Approximating edges of source bodies from magnetic or gravity anomalies: Geophysics, v. 51, p. 1494-1498.

Burns, L.E., 1982, Gravity and aeromagnetic modelling of a large gabbroic body near the Border Ranges fault, southern Alaska: U.S. Geological Survey Open-file Report 82-0460, 66 pp.

Cady, J.W., 1975, Magnetic and Gravity Anomalies in the Great Valley and Western Sierra Nevada Metamorphic Belt, California: Geological Society of America Special Paper 168, 56 pp.

Case, J.E., Burns, L.E., and Winkler, G.R., 1985, Maps showing aeromagnetic survey and geologic interpretation of the Valdez quadrangle, Alaska: U.S. Geological Survey Map MF-1714, scale 1:250,000, 2 sheets.

Coleman, R.G., 1996, Prospecting for ophiolites in the California continental margin: EOS, Trans. American Geophysical Union, v. 77, no. 46, suppl., p. 743.

Coleman, R.G., in press, Prospecting for ophiolites along the California continental margin: in Ophiolites and oceanic crust: New insights from field studies and ocean drilling program, Geological Society of America Special Publication, 21pp, 6 Figs.

Cordell, L., and Grauch, V.J.S., 1985, Mapping basement magnetization zones from aeromagnetic data in the San Juan basin, New Mexico, in Hinze, W.J., Ed., The utility of regional gravity and magnetic anomaly maps: Society of Exploration Geophysicists, p. 181-197.

Grantz, A., Zeitz, I., and Andreasen, G.E., 1963, An Aeromagnetic Reconnaissance of the Cook Inlet Area Alaska: U.S. Geological Survey Professional Paper 316-G, p. 117-134.

Griscom, A., and Case, J.E., 1983, Magnetic expression of geologic terranes in southern Alaska: Geophysics, v. 48, p. 444-445.

Haeussler, P.H., Bruhn, R.L., and Pratt, T.L., 2000, Potential seismic hazards and tectonics of upper Cook Inlet Basin, Alaska, based on analysis of Pliocene and younger deformation: Geological Society of America Bulletin, in press.

Magoon, L.B., Adkison, W.L., and Egbert, R.M., 1976, Map showing geology, wildcat wells, tertiary plant fossil localities, K-Ar age dates, and petroleum operations, Cook Inlet area, Alaska: USGS Map I-1019, scale $1: 250,000,3$ sheets.

Plafker, G., and Berg, H.C., 1994, Overview of the geology and tectonic evolution of Alaska, in Plafker, George, and Berg, H.C., eds., The geology of Alaska: Boulder, Colo., Geological Society of America, The Geology of North America, v. G-1, p. 989-1021.

Phillips, J.D., 1997, Potential-field geophysical software for the PC - version 2.2: U.S. Geological Survey 97-725, 34 p. (available on-line at $\mathrm{ftp} / / /$ geology.cr.usgs.gov/pub/open-file-reports/ofr-97-0725/ pfofr.htm)

Reid, A.B., 1980, Aeromagnetic survey design: Geophysics, v. 45, p. 973976.

Reid, A.B., Allsop, J.M., Granser, H., Millet, A.J., and Somerton, I.W., 1990, Magnetic interpretation in three dimensions using Euler Deconvolution: Geophysics, v. 55, p. 80-91.

Saltus, R.W., and Simmons, G.C., 1997, Composite and merged aeromagnetic data for Alaska - A web site for distribution of gridded data and plot files: U.S. Geological Survey Open-file report 97-0520 (http:// geology.cr.usgs.gov/pub/open-file-reports/ofr-97-0520/).

Saltus, R.W., Meyer, J.F., Jr., Barnes, D.F., and Morin, R.L., 1997, Tectonogeophysical domains of interior Alaska as interpreted from new gravity and aeromagnetic data compilation: in, Geological Studies in Alaska by the U.S. Geological Survey, Dumoulin, J.A., and Gray, J.E., eds., U.S. Geological Survey Professional Paper 1574, p. 157-171.

Saltus, R.W., Hudson, T.L., and Connard, G.G., 1999a, A New Magnetic View of Alaska: GSA Today, v. 9, no. 3, p. 1-6.

Saltus, R.W., Connard, G.G., and Hill, P.L., 1999b, Alaska Aeromagnetic Compilation - Digital Grids and Survey Data: U.S. Geological Survey Open-File Report 99-502, 1 CDROM.

Syberg, F.J.R., 1972, A Fourier method for the regional-residual problem of potential fields: Geophysical Prospecting, v. 20, p. 47-75.

Talwani, M., Worzel, J.L., and Landisman, M., 1959, Rapid gravity computations for two-dimensional bodies with application to the Mendocino submarine fracture zone: Journal of Geophysical research, v. 64, p. $49-59$.

Thompson, D.T., 1982, EULDPH: a new technique for making computerassisted depth estimates from magnetic data: Geophysics, v. 47, p. 31-37. 